\title{
Estimation of kinetic coefficients in micro-reactors for biodiesel synthesis: Bayesian inference with reduced mass transfer model
}

\author{
José Martim Costa Jr. ${ }^{b}$, Carolina P. Naveira-Cotta ${ }^{a, *}$ \\ a Laboratory of Nano- and Microfluidics and Microsystems, LabMEMS, Mechanical Engineering Dept. (PEM) \& \\ Nanoengineering Dept. (PENT) POLI\&COPPE, UFRJ, Universidade Federal do Rio de Janeiro, Cidade Universitária, Cx. \\ Postal 68503, 21945-970, Rio de Janeiro, RJ, Brazil \\ b Federal Institut of Sertão Pernambucano — IFSERTÃO, Rodovia PE 320, 56912-140, Serra Talhada, PE, Brazil
}

\section{A R T I C L E I N F O}

\section{Article history:}

Received 26 June 2018

Received in revised form 6

November 2018

Accepted 16 November 2018

Available online 23 November 2018

\section{Keywords:}

Biodiesel

Micro-reactor

Mass transfer

Lumped-differential formulation

Kinetic coefficients

Inverse problem

\begin{abstract}
A B $S T R A C T$
High yields in the production of biodiesel at very short residence times can be obtained by means of micro-reactors technology. The theoretical study of the reaction mechanisms involved in biodiesel synthesis in micro-reactors is crucial in achieving adequate design conditions towards maximizing biodiesel production. Such a physico-chemical phenomenon involves complex liquid-liquid flow and mass transfer processes, besides the transesterification reaction, and the determination of the kinetic coefficients is essential in using the mathematical models for the design of the micro-reactors. In this work, a nonlinear coupled mathematical model of first-order ordinary differential equations has been developed, using the Coupled Integral Equations Approach (CIEA) for model reduction, starting from a diffusive-convective-reactive three-dimensional mathematical model that describes the local species concentrations involved in the biodiesel synthesis. The ODEs system is numerically solved using the NDSolve routine of the Mathematica platform. The Markov Chain Monte Carlo method (MCMC) is employed in solving the inverse problem to estimate the kinetic coefficients, using synthetic experimental data with low conversion rates, which maximize the presence of intermediate species and increase the sensitivity of the problem to the desired parameters. The results presented indicate that the CIEA in combination with the MCMC statistical inference yield an efficient and robust combination for the direct - inverse analysis of such reactive mass transfer problems.
\end{abstract}

() 2018 Institution of Chemical Engineers. Published by Elsevier B.V. All rights reserved.

\section{Introduction}

The development of alternative sources of fuel, such as biodiesel, has been progressively motivated by growing concerns about the decline in petroleum reserves, the cost of petroleum, and the increase in environmental problems generated mainly by pollution from fossil fuel combustion (Dennis et al., 2008; Sun et al., 2010; Leung et al., 2010).

Biodiesel is an alternative fuel and has as its main characteristics to be environmentally friendlier than diesel produced from petroleum, biodegradable and non-toxic (Meher et al., 2006; Dennis et al., 2008;
Gomez-Castro et al., 2013). It is a renewable energy source that can replace totally or partially the conventional diesel due to its similar properties, but presenting low emissions of carbon, sulfur, particulate matter, and unburned hydrocarbons (Xie et al., 2012).

Biodiesel is usually produced by the transesterification reaction of a vegetable oil or animal fat with alcohols, such as methanol or ethanol, using basic homogeneous catalysts such as sodium hydroxide ( $\mathrm{NaOH})$ and potassium hydroxide (KOH) (Sun et al., 2008, 2010).

It is usually produced on a commercial scale in conventional batch reactors and the transesterification process in these reactors results in

\footnotetext{
* Corresponding author.

E-mail address: carolina@mecanica.ufrj.br (C.P. Naveira-Cotta).
} https://doi.org/10.1016/j.cherd.2018.11.023

0263-8762/@ 2018 Institution of Chemical Engineers. Published by Elsevier B.V. All rights reserved. 


$\begin{array}{ll}\text { Nomenclature } \\ \text { C } & \text { Dimensional concentration }\left[\mathrm{mol} / \mathrm{m}^{3}\right] \\ \mathrm{D} & \text { Diffusion coefficient }\left[\mathrm{m}^{2} / \mathrm{s}\right] \\ \mathrm{F} & \text { Dimensionless concentration } \\ \overline{\overline{\mathrm{F}}} & \text { Vector of dimensionless concentration } \\ \mathrm{G} & \text { Dimensionless reaction kinetics term } \\ \mathrm{H} & \text { Micro-reactor height }[\mathrm{m}] \\ \mathrm{J} & \text { Sensitivity coefficients } \\ \mathrm{L} & \text { Micro-reactor length }[\mathrm{m}] \\ \mathrm{k} & \text { Kinetic coefficients }\left[\mathrm{m}^{3} /(\text { mol.s)] }\right. \\ \bar{k} & \text { Exponent of kinetic coefficients } \\ \mathrm{M} & \text { Total number of measurements } \\ \mathrm{N}_{\mathrm{p}} & \text { Total number of parameters } \\ \mathrm{N}_{\mathrm{S}} & \text { Total number of species } \\ \mathrm{P} & \text { Parameter to be estimated } \\ \mathrm{P} & \text { Parameters vector } \\ \mathrm{Q} & \text { Volumetric flow rate }\left[\mathrm{m}^{3} / \mathrm{s}\right] \\ \mathrm{R} & \text { Ideal gas constant in the Arrhenius equation } \\ & \text { [cal/(mol.K)] } \\ \mathrm{r}_{\mathrm{N}} & \text { Random variable from a normal distribution } \\ \mathrm{r}_{\mathrm{U}} & \text { Random variable from a uniform distribution } \\ \mathrm{T} & \left.\text { Temperature [ }{ }^{\circ} \mathrm{C} \text { ou } \mathrm{K}\right] \\ \mathrm{u} & \text { Dimensional velocity field }[\mathrm{m} / \mathrm{s}] \\ \mathrm{U} & \text { Dimensionless velocity field } \\ \mathrm{Y} & \text { Measurements vector } \\ \mathrm{W} & \text { Width of the micro-reactor }[\mathrm{m}] \\ \mathrm{W} & \text { Matrix of measurements covariance } \\ \mathrm{X}, \mathrm{y}, \mathrm{z} & \text { Spatial variables } \\ \mathrm{X}, \mathrm{Y}, \mathrm{Z} & \text { Dimensionless spatial variables } \\ & \end{array}$

Greek symbols

$\triangle \mathrm{P} \quad$ Pressure drop $[\mathrm{Pa}]$

$\sigma \quad$ Standard deviation

$\rho \quad$ Density $\left[\mathrm{kg} / \mathrm{m}^{3}\right]$

$\mu \quad$ Dynamic viscosity [Pa.s]

$\varepsilon \quad$ Perturbation of the parameters in sensitivity analysis

$\omega \quad$ Search step

\begin{tabular}{ll}
\multicolumn{2}{l}{ Subscripts and superscripts } \\
A $\quad$ Alcohol \\
B & Biodiesel \\
DG & Diglyceride \\
i, j, m, ns & Counters \\
GL & Glycerol \\
MG & Monoglyceride \\
S & Species \\
T & Transposed \\
TG & Triglyceride \\
- & Average potential resulting from lumping pro- \\
& cedure
\end{tabular}

high residence times (from one to several hours) and high temperatures (Demirbas, 2008; Wen et al., 2009; Charoenwat and Dennis, 2009). Due to the high residence times, many studies have been developed with the purpose of reducing this reaction time to improve the efficiency of biodiesel production (Pengmei et al., 2010; Falahati and Tremblay, 2012; Rahimi et al., 2014).

More recently, the micro-reactor technology has emerged as a promising and alternative way for a higher efficiency biodiesel production. The micro-reactors are usually characterized by a reaction system based on micro-channels or micro-tubes with internal hydraulic diam- eters under $1 \mathrm{~mm}$. Due to the higher surface area/volume ratio inherent to this scale, considerable enhancement on the heat and mass transfer can be promoted, even reducing the reaction time scales, and thus becoming an excellent alternative approach for the biodiesel production (Hessel et al., 2005; Kobayashi et al., 2006; Bothe et al., 2008; Kumar et al., 2011; Lee et al., 2011; Xie et al., 2012; Tiwari et al., 2018). On the other hand, the small amount of biodiesel produced by a single micro-reactor could be addressed as one possible disadvantage to this technology. However, this approach in fact offers the possibility of assembling a large number of micro devices in parallel to increase the throughput, with a smaller increase of the floor space and energy consumption, compared to the traditional batch reactors (Billo et al., 2015).

Some researchers have experimentally demonstrated the achievement of high conversion rates in short residence times within a micro-reactor for biodiesel synthesis via the transesterification route (Al-Dhubabian, 2005; Sun et al., 2008; Guan et al., 2009; Sun et al., 2009; Wen et al., 2009; Arias et al., 2012; Rahimi et al., 2014; Naveira-Cotta et al., 2015; Santana et al., 2016). Most of the previous works used methanol as the alcohol (Al-Dhubabian, 2005; Sun et al., 2008; Guan et al., 2009; Sun et al., 2009; Wen et al., 2009; Rahimi et al., 2014) and only a few works employed ethanol (Arias et al., 2012; Naveira-Cotta et al., 2015; Santana et al., 2016). Both alcohols (methanol and ethanol) are commonly used in the transesterification process (Ma and Hanna, 1999). In this work, the pair methanol-soybean oil was chosen to illustrate the methodology.

Nevertheless, in order to optimally design micro-reactors, the conditions for the most efficient biodiesel production in terms of the operating parameters such as residence time, reaction temperature, catalyst type and concentration, as well as the alcohol to oil molar ratio, should be determined via a mathematical model that accurately describes the chemical and physical phenomena involved. In this reaction-convection-diffusion model, the kinetic coefficients are essential parameters to be identified, since they allow to adequately quantify the chemical reaction rates, but to a certain extent depend on some operating conditions. Table 1 illustrates some typical values for the kinetic coefficients, for different combinations of alcohol and oil, and both for batch and micro-reactor biodiesel synthesis (Noureddini and Zhu, 1997; Al-Dhubabian, 2005; Silva et al., 2008; Richard et al., 2013). The enhanced transport conditions within the micro-reactor may significantly alter the residence times in comparison to those values usually reported for the batch reactor.

The estimation of the kinetic coefficients requires the solution of the associated inverse problem for mass transfer within the microscale. Some studies on parameter estimation were carried out using optimization of an objective function (Al-Dhubabian, 2005; Dennis et al., 2008; Richard et al., 2013; Pontes and Naveira-Cotta, 2016). However, very few works in the literature addressed the estimation of kinetic coefficients involved in the biodiesel transesterification reaction within the micro-reactor framework (Al-Dhubabian, 2005; Dennis et al., 2008; Richard et al., 2013; Schwarz et al., 2013; Pontes and NaveiraCotta, 2016, Santana et al., 2016; Santana et al., 2017). In addition, there are several possible combinations in terms of vegetable oil and catalyst that remain untouched in the available literature.

The present work aims to contribute with a methodology to simultaneously estimate all kinetic coefficients involved in a mathematical model for second-order chemical reactions, with nonlinear coupling of the species balance equations, as required to simulate the transesterification reaction. The novelty here presented resides in the use of low conversion rate experiments to enhance the presence of the intermediate species, thus increasing the sensitivity of the problem to the parameters to be simultaneously estimated, combined with the proposition of a reduced lumped-differential model reformulated through the Coupled Integral Equations Approach (CIEA) (Cotta and Mikhailov, 1997), that captures the relevant information on the physical-chemical phenomena. The reduced model markedly decreases the computational cost usually involved in an inverse problem solution, resulting in an interesting and effective approach to carry out the inverse analysis in such class of problems. The inverse problem solution is then car- 
Table 1 - Comparison of kinetic coefficients in the macroscale and microscale using ethyl and methyl routes from

literature data.

\begin{tabular}{|c|c|c|c|c|}
\hline Parameters & Methyl route macro-scale ${ }^{a}$ & Methyl route micro-scale ${ }^{b}$ & Ethyl route macro-scale ${ }^{c}$ & Ethyl route micro-scale \\
\hline Oil & Soybean & Soybean & Castor & Sunflower \\
\hline Alcohol & Methanol & Methanol & Ethanol & Ethanol \\
\hline Catalyst & $\mathrm{NaOH} / 0.2 \mathrm{wt} \%$ & $\mathrm{NaOH} / 1 \mathrm{wt} \%$ & $\mathrm{NaOH} / 1 \mathrm{wt} \%$ & EtONa/1 wt\% \\
\hline Temperature & $50^{\circ} \mathrm{C}$ & $25^{\circ} \mathrm{C}$ & $50^{\circ} \mathrm{C}$ & $65^{\circ} \mathrm{C}$ \\
\hline Agitation & $300 \mathrm{rpm}$ & - & $400 \mathrm{rpm}$ & - \\
\hline $\mathrm{k}_{1}$ & $8.33 \times 10^{-4}\left[\mathrm{~L}^{2} / \mathrm{mol}^{2} \mathrm{~s}\right]$ & $4.37 \times 10^{-3}[\mathrm{~L} / \mathrm{mol} . \mathrm{s}]$ & $7.92 \times 10^{-3}[\mathrm{~L} / \mathrm{mol} . \mathrm{s}]$ & $5.0 \times 10^{-2}\left[\mathrm{~L}^{2} / \mathrm{mol}^{2} . \mathrm{s}\right]$ \\
\hline $\mathrm{k}_{2}$ & $1.83 \times 10^{-3}\left[\mathrm{~L}^{2} / \mathrm{mol}^{2} \mathrm{~s}\right]$ & $9.62 \times 10^{-3}[\mathrm{~L} / \mathrm{mol} . \mathrm{s}]$ & $9.483 \times 10^{-4}[\mathrm{~L} / \mathrm{mol} . \mathrm{s}]$ & $1.0 \times 10^{-10}\left[\mathrm{~L}^{2} / \mathrm{mol}^{2} . \mathrm{s}\right]$ \\
\hline $\mathrm{k}_{3}$ & $3.58 \times 10^{-3}\left[\mathrm{~L}^{2} / \mathrm{mol}^{2} \mathrm{~s}\right]$ & $1.88 \times 10^{-2}\left[\mathrm{~L} / \mathrm{mol} \_\mathrm{s}\right]$ & $2.29 \times 10^{-2} \quad[\mathrm{~L} / \mathrm{mol} . \mathrm{s}]$ & $1.5 \times 10^{-1}\left[\mathrm{~L}^{2} / \mathrm{mol}^{2} . \mathrm{s}\right]$ \\
\hline $\mathrm{k}_{4}$ & $2.05 \times 10^{-2}\left[\mathrm{~L}^{2} / \mathrm{mol}^{2} \mathrm{~s}\right]$ & $1.07 \times 10^{-1}\left[\mathrm{~L} / \mathrm{mol}_{-} \mathrm{s}\right]$ & $1.92 \times 10^{-2}[\mathrm{~L} / \mathrm{mol} . \mathrm{s}]$ & $7.0 \times 10^{-2}\left[\mathrm{~L}^{2} / \mathrm{mol}^{2} . \mathrm{s}\right]$ \\
\hline $\mathrm{k}_{5}$ & $4.03 \times 10^{-3}\left[\mathrm{~L}^{2} / \mathrm{mol}^{2} \mathrm{~s}\right]$ & $2.12 \times 10^{-2}[\mathrm{~L} / \mathrm{mol} . \mathrm{s}]$ & $5.75 \times 10^{-4}[\mathrm{~L} / \mathrm{mol} . \mathrm{s}]$ & $5.0 \times 10^{-2}\left[\mathrm{~L}^{2} / \mathrm{mol}^{2} . \mathrm{s}\right]$ \\
\hline $\mathrm{k}_{6}$ & $1.17 \times 10^{-4}\left[\mathrm{~L}^{2} / \mathrm{mol}^{2} \mathrm{~s}\right]$ & $9.0 \times 10^{-4}[\mathrm{~L} / \mathrm{mol} . \mathrm{s}]$ & $7.0 \times 10^{-4}[\mathrm{~L} / \mathrm{mol} . \mathrm{s}]$ & $1.5 \times 10^{-4}\left[\mathrm{~L}^{2} / \mathrm{mol}^{2} \cdot \mathrm{s}\right]$ \\
\hline
\end{tabular}

a Noureddini and Zhu (1997).

b Al-Dhubabian (2005).

c Silva et al. (2008).

d Richard et al. (2013).

$$
\begin{aligned}
& \text { Triglyceride }(\mathrm{TG})+\operatorname{Alcohol}(\mathrm{A}) \underset{k_{2}}{\stackrel{k_{1}}{\rightleftarrows}} \text { Diglyceride }+ \text { Ester }(\mathrm{B}) \\
& \text { Diglyceride (DG) + Alcohol (A) } \underset{k_{4}}{\stackrel{k_{s}}{\rightleftarrows}} \text { Monoglyceride + Ester(B) } \\
& \text { Monoglyceride(MG) }+ \text { Alcohol (A) } \underset{k_{4}}{\stackrel{k_{4}}{\rightleftarrows}} \text { Glycerol (GL)+Ester(B) }
\end{aligned}
$$

Fig 1 - Scheme of the transesterification reaction.

ried out through a Bayesian inference approach via the Markov Chain Monte Carlo (MCMC) method.

\section{Direct problem}

Biodiesel is usually obtained through transesterification which is a reversible reaction that occurs in three consecutive steps. In the first step, diglyceride (DG) is obtained from the reaction of alcohol (A) with the triglycerides (TG); in the second step, monoglycerides (MG) are produced from the reaction of alcohol with the diglycerides; and, in the last step, glycerol (GL) is obtained from the reaction of alcohol with the monoglycerides. In all three steps of the reaction, fatty acid esters (Biodiesel) are obtained, ethyl ester in case of the use of ethanol and methyl ester if methanol is used as alcohol (Richard et al., 2013; Schwarz et al., 2013). Fig. 1 shows the three consecutive steps of the transesterification reaction, where $\mathrm{k}_{1}$ through $\mathrm{k}_{6}$ represent the six kinetic coefficients to be estimated.

The reduced mathematical model described in this work is developed from a nonlinear coupled three-dimensional mathematical model that governs the steady local concentrations of the species involved in the transesterification reaction within a micro-reactor of rectangular cross section. It is assumed that the flow pattern of the two immiscible fluids (vegetable oil and alcohol) is laminar, stratified, and fully developed. Thus, the velocity profile for the triglyceride and alcohol phases in the micro-reactor can be analytically described, respectively, by Pontes et al. (2017):

$$
\begin{aligned}
& u_{\mathrm{TG}}(y, z)=\sum_{i=1}^{\infty}\left(\frac{2}{w}\right)^{1 / 2} \sin \left(\frac{i \pi}{w} z\right) S_{i}\left\{\left(1+\frac{\mu_{\mathrm{A}}}{\mu_{\mathrm{TG}}}\right)\left[-\sinh \left(\frac{H i \pi}{w}\right)+\sinh \left(\frac{i \pi(H-y)}{w}\right)\right]+\right. \\
& +\left(\frac{\mu_{\mathrm{A}}}{\mu_{\mathrm{TG}}}-1\right)\left[\sinh \left(\frac{\left(H-2 H_{\mathrm{TG}}\right) i \pi}{w}\right)+\sinh \left(\frac{i \pi\left(H-H_{\mathrm{TG}}+y\right)}{w}\right)+\right. \\
& \left.\left.-\sinh \left(\frac{i \pi\left(H-H_{\mathrm{TG}}-\mathrm{y}\right)}{w}\right)-\sinh \left(\frac{i \pi\left(H-2 H_{\mathrm{TG}}+y\right)}{w}\right)\right]+2 \sinh \left(\frac{i \pi y}{w}\right)\right\}
\end{aligned}
$$

$$
\begin{aligned}
& u_{A}(y, z)=\sum_{i=1}^{\infty}\left(\frac{2}{w}\right)^{1 / 2} \sin \left(\frac{i \pi}{w} z\right) S_{i}\left\{\left(1+\frac{\mu_{T G}}{\mu_{A}}\right)\left[-\sinh \left(\frac{H i \pi}{w}\right)+\sinh \left(\frac{i \pi y}{w}\right)\right]+\right. \\
& +\left(1-\frac{\mu_{T G}}{\mu_{A}}\right)\left[\sinh \left(\frac{\left(H-2 H_{T G}\right) i \pi}{w}\right)+\sinh \left(\frac{i \pi\left(2 H_{T G}-y\right)}{w}\right)+\right. \\
& \left.\left.-\sinh \left(\frac{i \pi\left(H-H_{T G}-y\right)}{w}\right)-\sinh \left(\frac{i \pi\left(H+H_{T G}-y\right)}{w}\right)\right]+2 \sinh \left(\frac{i \pi(H-y)}{w}\right)\right\}
\end{aligned}
$$

where

$S_{i}=\frac{-2 \sqrt{2} w^{5 / 2} \Delta P}{i^{3} L \pi^{3}\left[\left(\mu_{T G}-\mu_{A}\right) \sinh \left(\frac{\left(H-2 H_{T G}\right) i \pi}{w}\right)+\left(\mu_{T G}+\mu_{A}\right) \sinh \left(\frac{H i \pi}{w}\right)\right]}$

for $i=1,3,5, \ldots$

The two fluids here considered are soybean oil (triglycerides) and methanol, with sodium hydroxide as catalyst. $\mu_{\mathrm{TG}}$ and $\mu_{\mathrm{A}}$ are the dynamic viscosities of the oil and alcohol. $\mathrm{H}$ and $\mathrm{H}_{\mathrm{TG}}$ are the heights of the micro-channel and of the fluids interface, $\mathrm{L}$ and $\mathrm{w}$ are the length and width of the microreactor, respectively, and $\Delta \mathrm{P}$ is the total pressure drop along the micro-reactor.

The height of the triglyceride layer, $\mathrm{H}_{\mathrm{TG}}$, is determined from the ratio between the volumetric flow rates of the two fluids in the micro-reactor, and can be implicitly calculated from Eq. (2) below, knowing the imposed volumetric flow rates and the dynamic viscosities of each fluid:

$$
\frac{Q_{T G}}{Q_{A}}=\frac{w H_{T G}\left(\frac{1}{w H_{T G}} \int_{0}^{w} \int_{0}^{H_{T G}} u_{T G}(y, z) d y d z\right)}{w\left(H-H_{T G}\right)\left(\frac{1}{w\left(H-H_{T G}\right)} \int_{0}^{w} \int_{H_{T G}}^{H} u_{A}(y, z) d y d z\right)}=\frac{\int_{0}^{w} \int_{0}^{H_{T G}} u_{T G}(y, z) d y d z}{\int_{0}^{w} \int_{H_{T G}}^{H} u_{A}(y, z) d y d z}
$$

where $\mathrm{Q}_{\mathrm{TG}}$ and $\mathrm{Q}_{\mathrm{A}}$ are the volumetric flow rates of triglyceride and alcohol, respectively. The pressure drop can be determined by isolating $\Delta \mathrm{P}$ in the volumetric flow rate of the triglyceride phase.

Regarding the mathematical model for the mass transfer process, the assumption of constant physical properties has been used in different contributions (Al-Dhubabian, 2005; Pontes et al., 2016; Pontes et al., 2017) based on the findings of (Galante, 2012), who has observed that the use of variable physical properties did not influence the results, with no significant changes in the reactive flow or in the concentration 
profiles of the components involved in the reaction. In this sense, the present work has implemented a mathematical model for the mass transfer process assuming steady-state isothermal system and constant physical properties. The kinetic equations are obtained assuming second order consecutive elementary and reversible reactions, which were written as source terms in the mass transfer equations for the species concentrations. It is also assumed that the reactive effects occur predominantly in the triglyceride phase. A simplified kinetic equations model was adopted including the six main species into the reaction and incorporating the effect of the catalyst into the six kinetic coefficients to be estimated. Thus, the dimensionless convective-reactive-diffusive mass transfer equations for the species concentrations within the microreactor become:

$$
\begin{aligned}
& U_{T G}(Y, Z) \frac{\partial F_{s}(X, Y, Z)}{\partial X} \\
& =\xi_{s}\left(\gamma \frac{\partial^{2} F_{s}(X, Y, Z)}{\partial X^{2}}+\frac{\partial^{2} F_{s}(X, Y, Z)}{\partial Y^{2}}+\delta \frac{\partial^{2} F_{s}(X, Z)}{\partial Z^{2}}\right)+\varsigma G_{s},
\end{aligned}
$$

where $\mathrm{s}=\mathrm{TG}$, DG, MG, A, GL, B for $0<\mathrm{X}<1,<0<\mathrm{Y}<1,0<\mathrm{Z}<1$

$$
\mathrm{F}_{\mathrm{TG}}(0, \mathrm{Y}, \mathrm{Z})=1, \mathrm{~F}_{\mathrm{S}}(0, \mathrm{Y}, \mathrm{Z})=0 \text {, }
$$$$
\text { where } \mathrm{s}=\mathrm{A}, \mathrm{DG}, \mathrm{MG} \text {, GL, B, for } 0<\mathrm{Y}<1,0<\mathrm{Z}<1
$$

$\left.\frac{\partial \mathrm{F}_{\mathrm{S}}}{\partial \mathrm{X}}\right|_{\mathrm{X}=1}=0$, where s=A, TG, DG, MG, GL, B for $0<\mathrm{Y}<1,0<\mathrm{Z}<1$

$\left.\frac{\partial \mathrm{F}_{\mathrm{s}}}{\partial \mathrm{Y}}\right|_{\mathrm{Y}=0}=0$, where $\mathrm{s}=\mathrm{A}, \mathrm{TG}, \mathrm{DG}, \mathrm{MG}, \mathrm{GL}, \mathrm{B}$ for $0<\mathrm{X}<1,0<\mathrm{Z}<1$

$$
\left.\frac{\partial \mathrm{F}_{\mathrm{s}}}{\partial \mathrm{Z}}\right|_{\mathrm{Z}=0}=\left.\frac{\partial \mathrm{F}_{\mathrm{s}}}{\partial \mathrm{Z}}\right|_{\mathrm{Z}=1}=0 \text {, where } \mathrm{s}=\mathrm{A}, \mathrm{TG}, \mathrm{DG}, \mathrm{MG}, \mathrm{GL}, \mathrm{B}
$$$$
\text { for } 0<\mathrm{X}<1,<0<\mathrm{Y}<1
$$

$$
\begin{aligned}
& \mathrm{F}_{\mathrm{A}}(\mathrm{X}, 1, \mathrm{Z})=\mathrm{F}_{\mathrm{A}_{0}} ;\left.\frac{\partial \mathrm{F}_{\mathrm{S}}}{\partial \mathrm{Y}}\right|_{\mathrm{Y}=1}=0 \text {, where } \\
& \quad \mathrm{S}=\mathrm{TG}, \mathrm{DG}, \mathrm{MG}, \mathrm{GL}, \mathrm{B} \text { for } 0<\mathrm{X}<1,<0<\mathrm{Z}<1
\end{aligned}
$$

in which $F_{\mathrm{S}}$ represents the dimensionless concentration of the species "s" and $\mathrm{G}_{\mathrm{s}}$ represents the relations of the reactions for species " $s$ " involved in the transesterification process. Table 2 summarizes the expressions for $\mathrm{G}_{\mathrm{s}}$.

The associated dimensionless groups are given by:

$$
\begin{aligned}
& F_{T G}=\frac{C_{T G}}{C_{T G o}} ; \quad F_{A}=\frac{C_{A}}{C_{T G o}} ; \quad F_{D G}=\frac{C_{D G}}{C_{T G o}} ; \quad F_{M G}=\frac{C_{M G}}{C_{T G o}} ; \\
& F_{B}=\frac{C_{B}}{C_{T G o}} ; \quad F_{G L}=\frac{C_{G L}}{C_{T G o}} ; \quad F_{A o}=\frac{C_{A}^{*}}{C_{T G o}} \\
& Y=\frac{y}{H_{T G}} ; \quad X=\frac{x}{L} ; \quad Z=\frac{z}{w} ; \quad U_{T G}(Y, Z)=u_{T G}(Y, Z) ; \\
& \varsigma=L C_{T G o} ; \quad \xi_{s}=\frac{L D_{s}}{H_{T G}^{2}} ; \quad \gamma=\frac{H_{T G}^{2}}{L^{2}} ; \\
& \delta=\frac{H_{T G}^{2}}{w^{2}}
\end{aligned}
$$

where $C$ represents the concentration and $D$ represents the mass diffusion coefficient of each species.
Table 2 - Kinetic relationships for the different species in the transesterification reaction (Pontes et al., 2015).

\begin{tabular}{ll} 
Species, s. & G \\
\hline TG & $-k_{1} F_{T G} F_{A}+k_{2} F_{D G} F_{B}$ \\
A & $\left(-k_{1} F_{T G}-k_{3} F_{D G}-k_{5} F_{M G}\right) F_{A}+\left(k_{2} F_{D G}+k_{4} F_{M G}+k_{6} F_{G L}\right) F_{B}$ \\
DG & $\left(k_{1} F_{T G}-k_{3} F_{D G}\right) F_{A}+\left(-k_{2} F_{D G}+k_{4} F_{M G}\right) F_{B}$ \\
MG & $\left(k_{3} F_{D G}-k_{5} F_{M G}\right) F_{A}+\left(-k_{4} F_{M G}+k_{6} F_{G L}\right) F_{B}$ \\
GL & $k_{5} F_{M G} F_{A}-k_{6} F_{G L} F_{B}$ \\
B & $\left(k_{1} F_{T G}+k_{3} F_{D G}+k_{5} F_{M G}\right) F_{A}+\left(-k_{2} F_{D G}-k_{4} F_{M G}-k_{6} F_{G L}\right) F_{B}$ \\
\hline
\end{tabular}

The three-dimensional partial differential model in Eq. (3) can be reformulated as a lumped-differential system through the Coupled Integral Equations Approach - CIEA (Aparecido and Cotta, 1989; Cotta and Mikhailov, 1997; Naveira et al., 2009; Sphaier et al., 2017; Kakaç et al., 2018). The purpose of the CIEA is to reduce the original mathematical model by eliminating one or more spatial variables through lumping operations in the corresponding coordinate directions. In this way, a simplified formulation of the original partial differential system is obtained by reducing the number of independent variables on multidimensional situations, by averaging the partial differential equation into one or more spatial variables but retaining information in the integrated direction through the related boundary conditions. Different levels of approximation in such reformulation can be adopted, starting with the analysis of the classical lumped system analysis. However, improved formulations can be obtained by means of Hermite's approximation formulae for integrals, Cotta and Mikhailov (1997).

Following the CIEA approach, firstly the lumping was performed in the transverse direction ( $\mathrm{Z}$ coordinate), followed by the vertical direction ( $Y$ coordinate), considering the integrals that define the dimensionless average concentration and average mass flux of each species. The selected Hermite formulae for each pair of integrals are the approximations $\mathrm{H}_{1,1}$ and $\mathrm{H}_{0,0}$, which correspond to the corrected trapezoidal and trapezoidal integration rules, respectively (Cotta and Mikhailov, 1997; Sphaier et al., 2017).

The dimensionless average concentration in the transverse direction ( $Z$ coordinate), is given as:

$\bar{F}_{S}(X, Y) \equiv \frac{\int_{0}^{1} U_{T G}(Y, Z) F_{S}(X, Y, Z) d Z}{\int_{0}^{1} U_{T G}(Y, Z) d Z}$

Defining the Z-averaged velocity field as:

$\bar{U}_{T G}(Y)=\int_{0}^{1} U_{T G}(Y, Z) d Z$

Then, employing the corrected trapezoidal rule $\left(\mathrm{H}_{1,1}\right.$ approximation) to approximate the integral in the numerator of Eq. (5a), one finds:

$$
\begin{aligned}
& \bar{F}_{S}(X, Y) \approx \frac{1}{\bar{U}_{T G}(Y)}\left(\frac{1}{2}\left(U_{T G}(Y, 0) F_{S}(X, Y, 0)+U_{T G}(Y, 1) F_{s}(X, Y, 1)\right)\right. \\
& \left.\quad+\frac{1}{12}\left(\left.\frac{\partial U_{T G} F_{S}}{\partial Z}\right|_{Z=0}-\left.\frac{\partial U_{T G} F_{S}}{\partial Z}\right|_{Z=1}\right)\right)
\end{aligned}
$$


where $\mathrm{s}=\mathrm{TG}, \mathrm{DG}, \mathrm{MG}, \mathrm{A}, \mathrm{B}, \mathrm{GL}$

The dimensionless $Z$-averaged species mass flux is approximated by the trapezoidal rule $\left(\mathrm{H}_{0,0}\right.$ approximation), as shown below:

$$
\begin{aligned}
& \int_{0}^{1} \frac{\partial U_{T G} F_{s}(X, Y, Z)}{\partial Z} d Z \equiv\left[U_{T G}(Y, 1) F_{s}(X, Y, 1)-U_{T G}(Y, 0) F_{s}(X, Y, 0)\right] \cong \\
& \cong \frac{1}{2}\left(\left.\frac{\partial U_{T G} F_{s}}{\partial Z}\right|_{Z=0}+\left.\frac{\partial U_{T G} F_{S}}{\partial Z}\right|_{Z=1}\right)
\end{aligned}
$$

where $\mathrm{s}=\mathrm{TG}, \mathrm{DG}, \mathrm{MG}, \mathrm{A}, \mathrm{B}, \mathrm{GL}$

Eq. (3) are then reformulated by taking the average in the transverse direction, operating it with $\frac{\int_{0}^{1}(.) d z}{\overline{\mathrm{U}}_{T C}}$. Also, considering the fairly high values for the Péclet number typical of this application, as analyzed by Pontes et al. (2017), the longitudinal diffusion terms are neglected, and thus the following partially lumped system is reached:

$$
\begin{aligned}
& \bar{U}_{T G}(Y) \frac{\partial \bar{F}_{S}(X, Y)}{\partial X}=\xi_{s}\left(\frac{\partial^{2} A^{*}(Y) \bar{F}_{S}(X, Y)}{\partial Y^{2}}\right)+{ }^{2} B^{*}(Y) \bar{G}_{S} \\
& \text { where }=T G, D G, M G, A, G L, \text { ffor } 0<X<1,0<Y<1
\end{aligned}
$$

$\overline{\mathrm{F}}_{\mathrm{TG}}(0, \mathrm{Y})=1, \overline{\mathrm{F}}_{\mathrm{s}}(0, \mathrm{Y})=0$, where $=\mathrm{A}, \mathrm{DG}, \mathrm{MG}, \mathrm{GL}, \mathrm{B}$ for $0<\mathrm{Y}<1$

$$
\left.\frac{\partial \overline{\mathrm{F}}_{\mathrm{S}}}{\partial \mathrm{X}}\right|_{\mathrm{X}=1}=0 \text {, wheres }=\mathrm{A}, \mathrm{TG}, \mathrm{DG}, \mathrm{MG}, \mathrm{GL}, \mathrm{B} \text { for } 0<\mathrm{Y}<1
$$

$$
\left.\frac{\partial \bar{F}_{s}}{\partial \mathrm{Y}}\right|_{\mathrm{Y}=0}=0, \text { wheres }=\mathrm{A}, \mathrm{TG}, \mathrm{DG}, \mathrm{MG}, \mathrm{GL}, \mathrm{B} \text { for } 0<\mathrm{X}<1
$$

$$
\begin{aligned}
& \bar{F}_{A}(X, 1)=F_{A_{0}} ;\left.\quad \frac{\partial \bar{F}_{s}}{\partial Y}\right|_{Y=1}=0, \\
& \text { where }=\text { TG, DG, MG, GL, B for } 0<X<1
\end{aligned}
$$

where,

$$
\begin{aligned}
& A^{*}(Y)=3 \bar{U}_{T G}\left(\frac{1}{\left.\frac{\partial U_{T G}}{\partial Z}\right|_{Z=0}}-\frac{1}{\left.\frac{\partial U_{T G}}{\partial Z}\right|_{Z=1}}\right) \\
& B^{*}(Y)=18 \bar{U}_{T G}^{2}\left(\frac{1}{\left(\left.\frac{\partial U_{T G}}{\partial Z}\right|_{Z=0}\right)^{2}}-\frac{1}{\left(\left.\frac{\partial U_{T G}}{\partial Z}\right|_{Z=1}\right)^{2}}\right)
\end{aligned}
$$

Eq. (7) are now reformulated by taking the average in the vertical direction ( $\mathrm{Y}$ coordinate), employing the same approximations $\mathrm{H}_{1,1}$ and $\mathrm{H}_{0,0}$, for the average concentrations and fluxes, respectively, similarly to the lumping procedure for the transverse direction ( $\mathrm{Z}$ coordinate), and after some manipulation the following lumped-differential system is obtained:

$$
\overline{\bar{U}}_{T G} \frac{d \overline{\bar{F}}_{S}(X)}{d X}=\varsigma \overline{\bar{G}}_{s} \quad \text { wheres }=\text { TG, DG, MG, GL, B for } 0<X<1
$$

$\overline{\bar{U}}_{T G} \frac{d \overline{\bar{F}}_{A}(X)}{d X}=\xi_{A}\left(3 P^{*} \overline{\bar{F}}_{A}(X)+Q^{*}\right)+\varsigma \overline{\bar{G}}_{A} \quad$ for $0<X<1$

$\overline{\bar{F}}_{\mathrm{TG}}(0)=1, \quad \overline{\bar{F}}_{\mathrm{S}}(0)=0, \quad$ where $=\mathrm{A}, \mathrm{DG}, \mathrm{MG}, \mathrm{GL}, \mathrm{B}$

and,

$$
\begin{aligned}
\overline{\bar{U}}_{T G} & =\int_{0}^{1} \bar{U}_{T G}(Y) d Y, \quad P^{*}=\frac{-6 A^{*}(1) \overline{\bar{U}}_{T G}}{\bar{U}_{T G}(1)}, \\
Q^{*} & =A^{*}(1) F_{A_{0}}\left(4-\left.\frac{1}{\bar{U}_{T G}(1)} \frac{\partial \bar{U}_{T G}}{\partial Y}\right|_{Y=1}\right)
\end{aligned}
$$

where the double bars on the concentration and velocity fields correspond to the cross-section averaged ( $Z$ and $Y$ coordinates) quantities.

Eq (9b) for the alcohol differs from the equations for the other species, Eq. (9a), after application of the Hermite approximations in the $Y$ direction, due to the presence of a prescribed potential boundary condition at $Y=1\left(\bar{F}_{A}(X, 1)=F_{A_{0}}\right)$ instead of the no-flux boundary conditions for the other species $\left(\left.\frac{\partial \bar{F}_{S}}{\partial Y}\right|_{Y=1}=0\right)$, with $\mathrm{s}=\mathrm{DG}, \mathrm{MG}, \mathrm{GL}, \mathrm{B}$. Table 3 summarizes the final averaged expressions for the non-linear source terms $\overline{\bar{G}}_{s}$.where,

$M=\frac{-3 \overline{\bar{U}}_{\mathrm{TG}}^{2}\left(B(1)\left(\left.\frac{\partial \overline{\mathrm{U}}_{\mathrm{TG}}}{\partial \mathrm{Y}}\right|_{\mathrm{Y}=0}\right)^{2}+6 \mathrm{~B}(0) \overline{\mathrm{U}}_{\mathrm{TG}}(1)\left(\left.\frac{\partial \overline{\mathrm{U}}_{\mathrm{TG}}}{\partial \mathrm{Y}}\right|_{\mathrm{Y}=1}+2 \overline{\mathrm{U}}_{\mathrm{TG}}(1)\right)\right)}{\left(\left.\frac{\partial \overline{\mathrm{U}}_{\mathrm{TG}}}{\partial \mathrm{Y}}\right|_{\mathrm{Y}=0}\right)^{2} \bar{U}_{\mathrm{TG}}(1)\left(\left.\frac{\partial \overline{\mathrm{U}}_{\mathrm{TG}}}{\partial \mathrm{Y}}\right|_{\mathrm{Y}=1}-4 \bar{U}_{\mathrm{TG}}(1)\right)}$

$$
N=\frac{-F_{A_{0}} \overline{\bar{U}}_{T G}\left(12 B(0)\left(\bar{U}_{T G}(1)\right)^{2}\left(\left.\frac{\partial \bar{U}_{T G}}{\partial Y}\right|_{Y=1}-2 \bar{U}_{T G}(1)\right)\right.}{2\left(\left.\frac{\partial \bar{U}_{T G}}{\partial Y}\right|_{Y=0}\right)^{2} \bar{U}_{T G}(1)\left(\left.\frac{\partial \bar{U}_{T G}}{\partial Y}\right|_{Y=1}-4 \bar{U}_{T G}(1)\right)}
$$

$$
O=\frac{18 \overline{\bar{U}}_{T G}^{2}\left(B(1)\left(\left.\frac{\partial \bar{U}_{T G}}{\partial Y}\right|_{Y=0}\right)^{2}+B(0)\left(\left.\frac{\partial \bar{U}_{T G}}{\partial Y}\right|_{Y=1}-2 \bar{U}_{T G}(1)\right)^{2}\right)}{\left(\left.\frac{\partial \bar{U}_{T G}}{\partial Y}\right|_{Y=0}\right)^{2}\left(\left.\frac{\partial \bar{U}_{T G}}{\partial Y}\right|_{Y=1}-4 \bar{U}_{T G}(1)\right)^{2}}
$$

\section{Inverse problem}

\subsection{Sensitivity analysis}

Before addressing the estimation of the unknown parameters, the behavior of the determinant of the information matrix $\left(\mathrm{J}^{\mathrm{T}} \mathrm{J}\right)$ is analyzed, in order to inspect the influence of the parameters to be estimated in the solution of the inverse problem (Özisik and Orlande, 2000; Orlande et al., 2011).

The sensitivity matrix $\mathrm{J}$ is defined as:

$\mathrm{J}(\mathrm{P})=\left[\frac{\partial \overline{\overline{\mathrm{F}}}^{\mathrm{T}}(\mathrm{P})}{\partial \mathrm{P}}\right]^{\mathrm{T}}$

where the elements are

$J_{i, j}=\frac{\partial \overline{\bar{F}}_{i}}{\partial P_{j}}$

The sensitivity coefficient $\mathrm{J}_{\mathrm{i}, \mathrm{j}}$, as defined in Eq. (15), is a measure of the sensitivity of the estimated species concentration $\overline{\bar{F}}_{i}$ with respect to changes in the parameter $P_{j}$. The subscript 
Table 3 - Reformulated kinetic relationships for the different species in the transesterification reaction.

Species, s

TG

A

DG

MG

GL

B

\section{$\overline{\mathrm{G}}_{\mathrm{s}}$}

$-k_{1}\left(M \overline{\bar{F}}_{T G} \overline{\bar{F}}_{A}+N \overline{\bar{F}}_{T G}\right)+k_{2} O \overline{\bar{F}}_{D G} \overline{\bar{F}}_{B}$

$\left(-k_{1} \overline{\bar{F}}_{T G}-k_{3} \overline{\bar{F}}_{D G}-k_{5} \overline{\bar{F}}_{M G}\right) M \overline{\bar{F}}_{A}+\left(-k_{1} \overline{\bar{F}}_{T G}-k_{3} \overline{\bar{F}}_{D G}-k_{5} \overline{\bar{F}}_{M G}\right) N+$

$+\left(k_{2} \overline{\bar{F}}_{D G}+k_{4} \overline{\bar{F}}_{M G}+k_{6} \overline{\bar{F}}_{G L}\right) O \overline{\bar{F}}_{B}$

$\left(k_{1} \overline{\bar{F}}_{T G}-k_{3} \overline{\bar{F}}_{D G}\right) M \overline{\bar{F}}_{A}+\left(k_{1} \overline{\bar{F}}_{T G}-k_{3} \overline{\bar{F}}_{D G}\right) N+\left(-k_{2} \overline{\bar{F}}_{D G}+k_{4} \overline{\bar{F}}_{M G}\right) O \overline{\bar{F}}_{B}$

$\left(k_{3} \overline{\bar{F}}_{D G}-k_{5} \overline{\bar{F}}_{M G}\right) M \overline{\bar{F}}_{A}+\left(k_{3} \overline{\bar{F}}_{D G}-k_{5} \overline{\bar{F}}_{M G}\right) N+\left(-k_{4} \overline{\bar{F}}_{M G}+k_{6} \overline{\bar{F}}_{G L}\right) O \overline{\bar{F}}_{B}$

$k_{5} M \overline{\bar{F}}_{M G} \overline{\bar{F}}_{A}+k_{5} N \overline{\bar{F}}_{M G}-k_{6} \mathrm{O} \overline{\bar{F}}_{G L} \overline{\bar{F}}_{B}$

$\left(k_{1} \overline{\bar{F}}_{T G}+k_{3} \overline{\bar{F}}_{\mathrm{DG}}+k_{5} \overline{\bar{F}}_{\mathrm{MG}}\right) M \overline{\bar{F}}_{\mathrm{A}}+\left(k_{1} \overline{\overline{\mathrm{F}}}_{\mathrm{TG}}+k_{3} \overline{\overline{\mathrm{F}}}_{\mathrm{DG}}+k_{5} \overline{\overline{\mathrm{F}}}_{\mathrm{MG}}\right) \mathrm{N}+$

$+\left(-k_{2} \overline{\bar{F}}_{D G}-k_{4} \overline{\bar{F}}_{M G}-k_{6} \overline{\bar{F}}_{G L}\right) O \overline{\bar{F}}_{B}$ i refers to the rows in the sensitivity matrix and the i-th line refers to the measurement " $m$ " and the species "ns", given by the expression: $i=(m-1) N_{S}+n s$, for $m=1, \ldots, M$ and $n s=1,2$, $\ldots, N_{S}$, where, $N_{S}$ is the total number of species and $M$ is the total number of measurements. The subscript $j$ refers to the column of the sensitivity matrix for $j=1,2, \ldots, N_{p}$, where $N_{p}$ is the total number of parameters.

Small values of the $\mathrm{J}_{\mathrm{i}, \mathrm{j}}$ magnitude indicate that large variations in $\mathrm{P}_{\mathrm{j}}$ cause small changes in $\overline{\bar{F}}_{\mathrm{S}_{\mathrm{i}}}$. In such case, a good estimation of the parameter $P_{j}$ can be extremely difficult, basically because the same value of the potential can be obtained for a large range of values of $\mathrm{P}_{\mathrm{j}}$. In fact, in this situation when the sensitivity coefficients are small, we also have that the determinant of $J^{\mathrm{T}} \mathrm{J}\left(\left|\mathrm{J}^{\mathrm{T}} \mathrm{J}\right|\right)$ is approximately zero, $\left|\mathrm{J}^{\mathrm{T}} \mathrm{J}\right| \approx 0$, and in this case the inverse problem is considered to be illconditioned (Özisik and Orlande, 2000; Orlande et al., 2011). It can also be shown that $\left|\mathrm{J}^{\mathrm{T}} \mathrm{J}\right|$ is null when a column of $\mathrm{J}$ can be expressed as a linear combination of other columns. Thus, it is desirable to have linearly independent sensitivity coefficients of large magnitudes, so that an accurate estimation of the parameters can be obtained.

In problems involving parameters with different orders of magnitude, the sensitivity coefficients with respect to the various parameters may be different in order of magnitude, thus creating difficulties in the comparison and identification of linear dependence. This difficulty can be alleviated by an analysis of the reduced sensitivity coefficients given by:

$J_{i, j}=P_{j} \frac{\partial \overline{\bar{F}}_{i}}{\partial P_{j}}$

The maximization of $\left|\mathrm{J}^{\mathrm{T}} \mathrm{J}\right|$ is generally used in optimal experiments for parameter estimation, because the confidence region of the estimates is minimized. Usually, the temporal variation of the sensitivity coefficients and the $\mathrm{J}^{\mathrm{T}} \mathrm{J}$ determinant is examined before starting the inverse problem solution itself. Such analyzes can indicate, for instance, the number of time measurements required in the inverse analysis, that correspond to linearly independent sensitivity coefficients with large absolute values and large magnitudes of the $\mathrm{J}^{\mathrm{T}} \mathrm{J}$ determinant (Özisik and Orlande, 2000; Orlande et al., 2011).

In the present study, the forward finite difference approximation is used to compute the sensitivity coefficients by approximating the first-order derivatives that appear in the definition of the sensitivity coefficients of Eq. (15), according to:

$J_{i, j} \cong \frac{\overline{\bar{F}}_{i}\left(P_{1}, P_{2}, \ldots, P_{j}+\varepsilon P_{j}, \ldots, P_{N_{p}}\right)-\overline{\bar{F}}_{i}\left(P_{1}, P_{2}, \ldots, P_{j}, \ldots, P_{N_{p}}\right)}{\varepsilon P_{j}}$ where $\varepsilon$ is the disturbance on the parameter and $N_{p}$ is the total number of parameters.

The parameters to be estimated in vector $\mathbf{P}=\left[\bar{k}_{1}, \overline{\mathrm{k}}_{2}, \overline{\mathrm{k}}_{3}\right.$, $\left.\overline{\mathrm{k}}_{4}, \overline{\mathrm{k}}_{5}, \overline{\mathrm{k}}_{6}\right]$, correspond in fact to exponents, since the original kinetic coefficients can be expressed in the form given by:

$$
k_{j}=10^{\bar{k}_{j}} \quad \text { for } j=1,2, \ldots, 6
$$

The explanation for this choice resides in the sensitivity analysis of the problem, which showed a more adequate sensitivity for the exponent coefficients in the base 10, than for the original kinetic coefficients themselves.

\subsection{Markov Chain Monte Carlo Method (MCMC)}

The solution of the inverse problem here addressed was obtained within the Bayesian inference framework making use of the Markov Chain Monte Carlo method. In essence, the Bayesian statistics approach permits the use of all available information to reduce the uncertainty in the inference or decision-making problem.

A Bayesian estimator is basically concerned with the analysis of the posterior probability density, which is the conditional probability of the parameters given the measurements, while the likelihood is the conditional probability of the measurements given the parameters. If we assume the parameters and the measurement errors to be independent Gaussian random variables, with known means and covariance matrices, and that the measurement errors are additive, a closed form expression can be derived for the posterior probability density. In this case, the estimator that maximizes the posterior probability density can be recast in the form of a minimization problem involving the maximum a posteriori objective function. On the other hand, if different prior probability densities are assumed for the parameters, the posterior probability distribution may not allow for an analytical treatment. In this case, the Markov Chain Monte Carlo (MCMC) method can be used to draw samples of all possible parameters, so that inference on the posterior probability becomes inference on the samples.

In the Bayesian framework, the mechanism for combining the information provided by the measurements with any prior available information on the unknown parameters, is through the well-known Bayes' formula (Gamerman and Lopes, 2006; Liang et al., 2010):

$\pi_{\text {posteriori }}(\mathrm{P})=\pi(\mathrm{P} \mid \mathrm{Y})=\frac{\pi_{\text {prior }}(\mathrm{P}) \pi(\mathrm{Y} \mid \mathrm{P})}{\pi(\mathrm{Y})}$

where $\pi_{\text {posteriori }}(\mathrm{P})$ is the posterior probability density, $\pi_{\text {prior }}(\mathrm{P})$ is the prior probability density for the parameters, $\pi(\mathrm{Y} \mid \mathrm{P})$ is the 
Table 4 - Data used to simulate the species concentrations involved in the transesterification reaction (Al-Dhubabian, 2005; Noureddini and $\mathrm{Zhu}, 1997)$.

\begin{tabular}{|c|c|c|c|}
\hline Param. & Value & Param. & Value $\left[\mathrm{m}^{3} /(\mathrm{mol} \mathrm{s})\right]$ \\
\hline Alcohol & Methanol & $\mathrm{k}_{1}$ & $4.368 \times 10^{-6}$ \\
\hline Oil & Soybean & $\mathrm{k}_{2}$ & $9.623 \times 10^{-6}$ \\
\hline $\mathrm{Q}_{\mathrm{TG}} / \mathrm{Q}_{\mathrm{A}}$ & 3.4 & $\mathrm{k}_{3}$ & $1.88 \times 10^{-5}$ \\
\hline$\mu_{\mathrm{TG}}$ & $5.825 \times 10^{-2}[\mathrm{~Pa} \mathrm{~s}]$ & $\mathrm{k}_{4}$ & $1.074 \times 10^{-4}$ \\
\hline$\mu_{\mathrm{A}}$ & $5.47 \times 10^{-4}[\mathrm{~Pa} \mathrm{~s}]$ & $\mathrm{k}_{5}$ & $2.117 \times 10^{-5}$ \\
\hline $\mathrm{D}_{\mathrm{TG}}$ & $1.58 \times 10^{-9}\left[\mathrm{~m}^{2} / \mathrm{s}\right]$ & $\mathrm{k}_{6}$ & $9.0 \times 10^{-7}$ \\
\hline$\rho_{\mathrm{TG}}$ & $885\left[\mathrm{~kg} / \mathrm{m}^{3}\right]$ & Reaction & Activation energy \\
\hline $\mathrm{D}_{\mathrm{A}}$ & $1.182 \times 10^{-10}\left[\mathrm{~m}^{2} / \mathrm{s}\right]$ & $\mathrm{TG} \rightarrow \mathrm{DG}$ & $13,145[\mathrm{cal} / \mathrm{mol}]$ \\
\hline $\mathrm{D}_{\mathrm{DG}}, \mathrm{D}_{\mathrm{MG}}, \mathrm{D}_{\mathrm{GL}}, \mathrm{D}_{\mathrm{B}}$ & $1.38 \times 10^{-9}\left[\mathrm{~m}^{2} / \mathrm{s}\right]$ & $\mathrm{DG} \rightarrow \mathrm{TG}$ & $9932[\mathrm{cal} / \mathrm{mol}]$ \\
\hline $\mathrm{C}_{\mathrm{TGO}}$ & $1014\left[\mathrm{~mol} / \mathrm{m}^{3}\right]$ & $\mathrm{DG} \rightarrow \mathrm{MG}$ & $19,860[\mathrm{cal} / \mathrm{mol}]$ \\
\hline $\mathrm{F}_{\mathrm{Ao}}$ & 4.4 & $\mathrm{MG} \rightarrow \mathrm{DG}$ & $14,639[\mathrm{cal} / \mathrm{mol}]$ \\
\hline \multirow[t]{2}{*}{$\mathrm{R}$} & $1.987[\mathrm{cal} /(\mathrm{mol} \mathrm{K})]$ & $\mathrm{MG} \rightarrow \mathrm{GL}$ & $6421[\mathrm{cal} / \mathrm{mol}]$ \\
\hline & & $\mathrm{GL} \rightarrow \mathrm{MG}$ & $9588[\mathrm{cal} / \mathrm{mol}]$ \\
\hline
\end{tabular}

likelihood function, and $\pi(\mathrm{Y})$ is the probability density of the measurements, which represents a normalization constant.

Assuming that the measurement errors are additive, uncorrelated, with Gaussian distribution, mean zero, and known covariance matrix, the likelihood function is given by:

$\pi(\mathrm{Y} \mid \mathrm{P})=(2 \pi)^{-\frac{1}{2}}|\mathrm{~W}|^{-\frac{1}{2}} \exp \left\{-\frac{1}{2}\left[\mathrm{Y}-\overline{\bar{F}}_{S}(\mathrm{P})\right]^{\mathrm{T}} \mathrm{W}^{-1}\left[\mathrm{Y}-\overline{\bar{F}}_{\mathrm{S}}(\mathrm{P})\right]\right\}$

where $\overline{\mathrm{F}}_{\mathrm{S}}(\mathrm{P})$ is the solution of the direct problem given by Eq. (9), obtained with a sample of the parameters vector, $\mathrm{P}$.

The Markov Chain Monte Carlo method (MCMC) is used to estimate the posterior probability density, which is constructed using sampling and rejection techniques. In order to implement the Markov chain, a density $\mathrm{q}\left(\mathrm{P}^{*}, \mathrm{P}^{(\mathrm{t}-1)}\right)$ is required, which gives the probability of changing from the current chain state, $\mathrm{P}^{(\mathrm{t}-1)}$, to the new state, $\mathrm{P}^{*}$. One of the most used algorithms for implementing the Monte Carlo method with Markov chains is that of Metropolis-Hasting, which follows the following steps (Kaipo and Somersalo, 2004):

1. Select a candidate $\mathrm{P}^{*}$ from the distribution $\mathrm{q}\left(\mathrm{P}^{*}, \mathrm{P}^{(\mathrm{t}-1)}\right)$, where the proposal of a candidate in the Markov chain is based on the random walk model with Gaussian distribution, in the following form:

$\mathrm{P}^{*}=\mathrm{P}^{(\mathrm{t}-1)}+\mathrm{P}^{(\mathrm{t}-1)} \omega \mathrm{r}_{\mathrm{N}}$

where $r_{N}$ is the random variable generated from a normal distribution with zero mean and unit standard deviation and $\omega$ is the search step;

2. Calculate the probability of acceptance $\alpha$ of the candidate value in the form:

$\alpha=\min \left[1, \frac{\pi\left(\mathbf{P}^{*} \mid \mathrm{Y}\right) \mathrm{q}\left(\mathrm{P}^{(\mathrm{t}-1)} \mid \mathbf{P}^{*}\right)}{\pi\left(\mathrm{P}^{(\mathrm{t}-1)} \mid \mathrm{Y}\right) \mathrm{q}\left(\mathbf{P}^{*} \mid \mathbf{P}^{(\mathrm{t}-1)}\right)}\right]$

3. A random number $r_{U}$ is generated from a uniform distribution, that is, $\mathrm{r}_{\mathrm{U}} \sim \mathrm{U}(0,1)$;

4. If $r_{U} \leq \alpha$, the new $P^{t}=P^{*}$ value is accepted. Otherwise $\mathrm{P}^{\mathrm{t}}=\mathrm{P}^{(\mathrm{t}-1)}$;

5. Return to step 1

\section{Results and discussion}

\subsection{Direct solution analysis}

In order to evaluate the reduced model, reformulated as a first order ordinary differential equations system, the evolution of triglycerides conversion was obtained for different residence times and at different reaction temperatures, using data obtained in the literature (Al-Dhubabian, 2005; Noureddini and Zhu, 1997) and summarized in Table 4.

The results obtained through the reduced model proposed in this work were verified controlling the error of the numerical solution with 8 significant digits and comparing the reformulated model via CIEA with the 3D model for square micro-reactors, with cross-sections of $400 \times 400 \mu \mathrm{m}$, and length $\mathrm{L}$ of $2.33 \mathrm{~cm}$.

Fig. 2(a-d) show the behavior of the triglyceride conversion for different residence times for the $400 \times 400 \mu \mathrm{m}$ square cross-section micro-reactor at different temperatures, $25^{\circ} \mathrm{C}$, $35^{\circ} \mathrm{C}, 45^{\circ} \mathrm{C}$, and $60^{\circ} \mathrm{C}$. In all sets of figures, the dashed lines represent the results achieved by the reduced model of Eq. (9), handled by the Mathematica's NDSolve routine (Wolfram, 2017), while the points represent results available in the literature (Pontes et al., 2017), from the solution of the threedimensional problem, Eq. (3), through the Generalized Integral Transformation Technique, GITT (Cotta, 1990; Cotta, 1993; Cotta and Mikhailov, 1997). Through Fig. 2 it can be observed the good agreement of the reduced model with the more complete 3D model. The verification of the reduced model opens up the possibility of using it in the estimation procedure of the kinetic coefficients, resulting in a tremendous reduction of the computational effort related to the inverse problem analysis.

\subsection{Sensitivity analysis}

The sensitivity analysis of the parameters was performed using the biodiesel synthesis from soybean oil and methanol at a molar ratio methanol/oil of 7.2/1 in a micro-channel of square section, for illustration the sensitivity analysis of a reactor of $400 \times 400 \mu \mathrm{m}$ is here presented. Table 5 shows the physical parameters used in the simulation of the species concentration fields.

As discussed in the previous section, it is desirable to have linearly independent sensitivity coefficients of large magnitudes, so that an accurate estimation of the parameters can be achieved. The parameters to be determined in this work are the kinetic coefficients, however, it has been observed that 

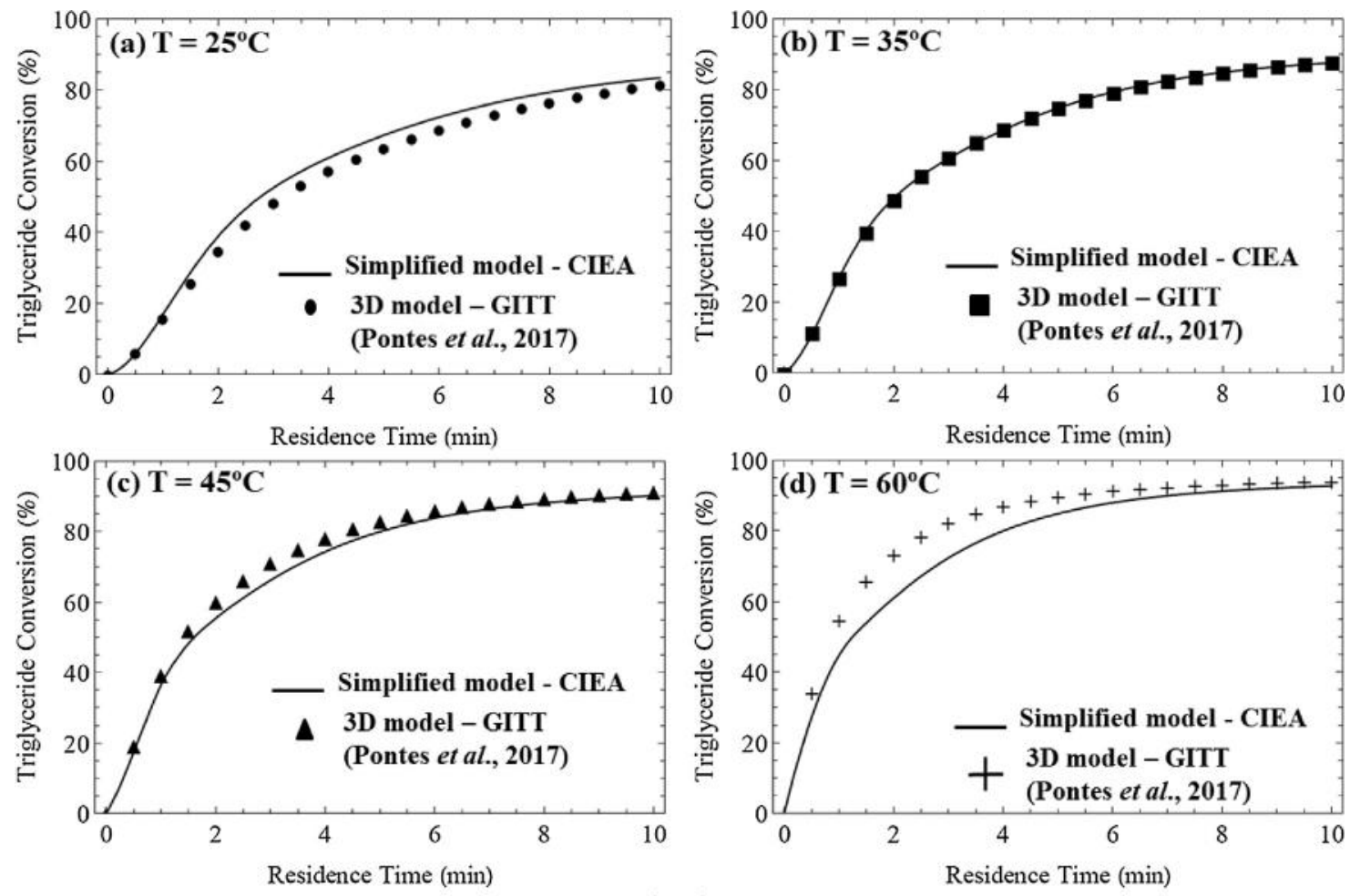

Fig. 2 - Comparison of the triglyceride conversion evolutions obtained through the reduced model via CIEA (present work) and through the three-dimensional model via GITT (Pontes et al., 2017), in a micro-reactor of square section $(400 \times 400 \mu \mathrm{m})$ for different temperatures: (a) $\mathrm{T}=25^{\circ} \mathrm{C}$, (b) $\mathrm{T}=35^{\circ} \mathrm{C}$, (c) $\mathrm{T}=45^{\circ} \mathrm{C}$, (d) $\mathrm{T}=60^{\circ} \mathrm{C}$.

\begin{tabular}{|c|c|c|c|}
\hline Parameters & Value & Parameters & Value \\
\hline$\mu_{\mathrm{TG}}[\mathrm{Pa} \mathrm{S}]$ & $5.825 \times 10^{-2}$ & $\mathrm{~L}[\mathrm{~m}]$ & $2.33 \times 10^{-2}$ \\
\hline$\mu_{\mathrm{A}}[\mathrm{PaS}]$ & $5.47 \times 10^{-4}$ & $\rho_{\mathrm{TG}}\left[\mathrm{kg} / \mathrm{m}^{3}\right]$ & 885 \\
\hline $\mathrm{D}_{\mathrm{A}}\left[\mathrm{m}^{3} / \mathrm{s}^{2}\right]$ & $1.182 \times 10^{-10}$ & $\rho_{\mathrm{A}}\left[\mathrm{kg} / \mathrm{m}^{3}\right]$ & 792 \\
\hline $\mathrm{Q}_{\mathrm{TG}} / \mathrm{Q}_{\mathrm{A}}$ & 3.4 & $\mathrm{w}[\mathrm{m}]$ & $400 \times 10^{-6}$ \\
\hline $\mathrm{C}_{\mathrm{TGo}}\left[\mathrm{mol} / \mathrm{m}^{3}\right]$ & 1014 & $\mathrm{H}[\mathrm{m}]$ & $400 \times 10^{-6}$ \\
\hline $\mathrm{F}_{\mathrm{Ao}}$ & 4.4 & $\mathrm{~T}\left[{ }^{\circ} \mathrm{C}\right]$ & 25 \\
\hline
\end{tabular}

working with an exponent algebraic representation (base 10) of these constants, Eq. (18), reduces the search region for the exponents $\overline{\mathrm{k}}_{i}$ and increases the possibility of identifying combinations of parameters that lead to better results. Thus, an analysis of the magnitude of the matrix determinant $\left|\mathrm{J}^{\mathrm{T}} \mathrm{J}\right|$ was performed to decide whether it would be more appropriate to estimate the kinetic coefficients directly or the respective exponents in the base 10 representation. Thus, the magnitude of $\left|J^{\mathrm{T}} \mathrm{J}\right|$ was calculated for both the kinetic coefficients and the respective exponents using the parameters described in Table 5 and considering the information on the concentrations of each species (TG, DG, MG, B, GL and A). Table 6 shows the exact values considered for the kinetic coefficients and their respective exponents.

The magnitude of $\left|\mathrm{J}^{\mathrm{T}} \mathrm{J}\right|$ for the original kinetic coefficients was computed as $1.549 \times 10^{-5}$, while the magnitude of $\left|J^{\mathrm{T}} \mathrm{J}\right|$ for the exponents of these constants was $5.555 \times 10^{7}$, that is, the magnitude of $\left|\mathrm{J}^{\mathrm{T}} \mathrm{J}\right|$ of the exponents of the kinetic coefficients was $3.587 \times 10^{12}$ times greater than the magnitude of the $\left|\mathrm{J}^{\mathrm{T}} \mathrm{J}\right|$ for the original kinetic coefficients. Therefore, it was concluded that it would be computationally more appropriate to estimate the exponents of the kinetic coefficients, $\overline{\mathrm{k}}_{i}$, and afterwards determine the final values of the kinetic coefficients through Eq. (18). Thus, a sensitivity analysis using
Table 6 - Adopted values for the kinetic coefficients and their respective exponents in the sensitivity analysis (Al-Dhubabian, 2005).

\begin{tabular}{ll}
$\begin{array}{l}\text { Original kinetic } \\
\text { coefficients }\left[\mathrm{m}^{3} /(\mathrm{mol} . \mathrm{s})\right]\end{array}$ & $\begin{array}{l}\text { Exponents of the } \\
\text { kinetic coefficients }\end{array}$ \\
\hline $\mathrm{k}_{1}=4.368 \times 10^{-6}$ & $\overline{\mathrm{k}}_{1}=-5.36$ \\
$\mathrm{k}_{2}=9.623 \times 10^{-6}$ & $\overline{\mathrm{k}}_{2}=-5.02$ \\
$\mathrm{k}_{3}=1.880 \times 10^{-5}$ & $\overline{\mathrm{k}}_{3}=-4.73$ \\
$\mathrm{k}_{4}=1.074 \times 10^{-4}$ & $\overline{\mathrm{k}}_{4}=-3.97$ \\
$\mathrm{k}_{5}=2.117 \times 10^{-5}$ & $\overline{\mathrm{k}}_{5}=-4.67$ \\
$\mathrm{k}_{6}=9.000 \times 10^{-7}$ & $\overline{\mathrm{k}}_{6}=-6.05$ \\
\hline
\end{tabular}

the reduced sensitivity coefficients was performed using the exponents of the kinetic coefficients as parameters to be estimated, using the parameters described in Tables 5 and 6 . In Fig. $3(\mathrm{a}-\mathrm{f})$ are shown the six reduced sensitivity coefficients for each species involved in the transesterification reaction (TG, A, DG, MG, B, GL) as a function of the residence time and at position $\mathrm{X}=1$, which corresponds to the outlet of the microreactor, where the average concentrations of the species are in fact experimentally obtained and using the parameter perturbation value, $\varepsilon$, equal to $10^{-5}$. With respect to the triglyceride (TG) species, shown in Fig. 3(a), it is observed that the parameters $\overline{\mathrm{k}}_{1}, \overline{\mathrm{k}}_{2}$, and $\overline{\mathrm{k}}_{6}$ are linearly independent while the other parameters are linearly dependent. For the diglyceride (DG) species, presented in Fig. $3 c, \overline{\mathrm{k}}_{1}$ and $\overline{\mathrm{k}}_{6}$ are linearly independent, while $\overline{\mathrm{k}}_{2}$ and $\overline{\mathrm{k}}_{5}$ are linearly dependent to each other, as well as $\overline{\mathrm{k}}_{3}$ and $\overline{\mathrm{k}}_{4}$. Fig. $3 \mathrm{~d}$ shows the sensitivity of the parameters in relation to the monoglyceride (MG) species, where it is noted that $\overline{\mathrm{k}}_{2}$ and $\overline{\mathrm{k}}_{6}$ are linearly independent and the other parameters are linearly dependent. For the glycerol (GL) species, shown in Fig. 3e, it is observed that only the parameter $\overline{\mathrm{k}}_{6}$ is linearly independent while the other parameters are linearly dependent. Fig. 3 f illustrates the sensitivity of the 

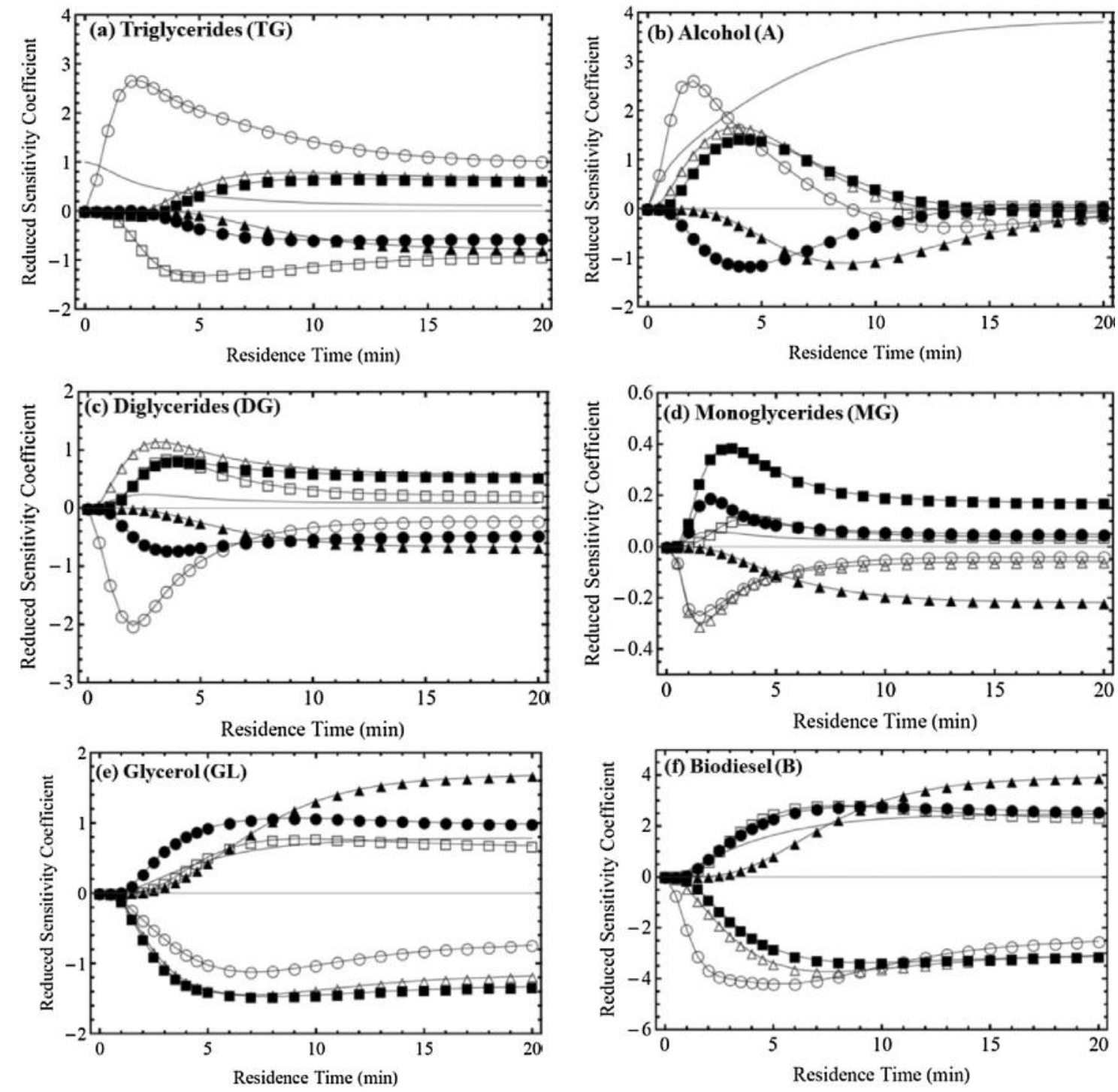

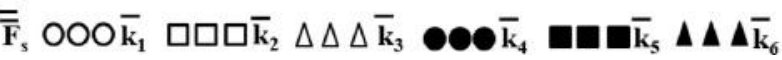

Fig. 3 - Reduced sensitivity coefficients along residence time for all six species involved in the transesterification reaction: (a) Triglycerides; (b) Alcohol; (c)Diglycerides; (d) Monoglycerides; (e) Glycerol; and, (f) Biodiesel.

parameters in relation to the biodiesel (B) species and it can be noticed that the parameters $\overline{\mathrm{k}}_{1}$ and $\overline{\mathrm{k}}_{6}$ are linearly independent and the others are linearly dependent. In relation to the alcohol (A) species, Fig. 3(b), it can be seen that some parameters are linearly independent while others are linearly dependent.

In view of this sensitivity analysis, it can be concluded that the magnitudes of the reduced sensitivity coefficients are higher at smaller values of residence time (up to $4 \mathrm{~min}$ in the majority of the analyzed cases) and, in addition, linear independence can only be warranted at these short times, when the estimation can be deemed more reliable. For longer times the parameters are linearly dependent.

Following the sensitivity analysis, the magnitude of the determinant of the matrix $\left|\mathrm{J}^{\mathrm{T}} \mathrm{J}\right|$ is examined in order to decide on the set of species concentration measurements to be used in the estimation procedure. Five different cases are considered: in the first case, it is assumed that only measurements of species B would be available for the estimation procedure; in the second case it is considered that measurements of two species, $\mathrm{B}$ and TG, would be used; the third case considers that measurements of four species, B, TG, DG and MG, would be available; in the fourth case, measurements of five species,
Table 7 - Cases and results for each set of species concentration measurements used in the analysis of the $\left|\mathrm{J}^{\mathrm{T}} \mathrm{J}\right|$ determinant.

\begin{tabular}{lll} 
Cases & Species & Determinant $\mathrm{J}^{\mathrm{T}} \mathrm{J}$ \\
\hline Case1 & B & $1.145 \times 10^{-2}$ \\
Case2 & B and TG & 707.78 \\
Case3 & B, TG, DG and MG & $1.327 \times 10^{7}$ \\
Case4 & B, TG, DG, MG and GL & $2.785 \times 10^{7}$ \\
Case5 & B, A, TG, DG, MG and GL & $2.814 \times 10^{7}$ \\
\hline
\end{tabular}

B, TG, DG, MG and GL, would be taken in account, and finally, in the fifth case, all six species concentrations (B, A, TG, DG, MG and GL) would be measured for the estimation procedure. Table 7 summarizes the cases for each set of measurements and the corresponding magnitude of the determinant $\left|J^{\mathrm{T}} \mathrm{J}\right|$. It can be seen that the magnitude of $\left|\mathrm{J}^{\mathrm{T}} \mathrm{J}\right|$ increases as additional species and the corresponding concentration measurements are added into the analysis, reaching the maximum magnitude in cases 4 and 5, while the difference of magnitudes between these two last cases is negligible. Thus, the importance of including the measurements of species B, TG, DG, 
MG, GL and A in the estimation of the parameters has been determined.

However, in the actual experimental procedure, the measurements of the concentration of the alcohol (A) and glycerol (GL) are not easy to be obtained, since both are removed from the final product of the biodiesel synthesis, which usually contains all the species involved in the transesterification reaction. In view of this, the estimates here analyzed will proceed considering case 3 of Table 7 .

\subsection{Parameters estimation}

The solution of the inverse problem is now demonstrated using synthetic concentration measurements of the species TG, DG, MG and B (case 3 of Table 7) obtained from the solution of the three-dimensional model, Eq. (3), via the Generalized Integral Transformation Technique (GITT), as in Pontes et al. (2017), avoiding in this way the so called inverse crime in the present inverse problem analysis. Synthetic measurements were generated by adding Gaussian errors with zero mean and constant standard deviation in the species concentration, in the form:

$\mathrm{Y}_{\mathrm{S}}=\mathrm{F}_{\mathrm{s} \text {,exact }}+\sigma_{\mathrm{s}, \text { measure }} \cdot \mathbf{r}_{\mathrm{N}}$

where $Y_{S}$ are the synthetic concentration measurements that contain the random errors, $F_{\mathrm{s} \text {,exact }}$ are the exact values of the species concentrations calculated from the solution of the 3D mathematical model, $\sigma_{\mathrm{s}, \text { measure }}$ is the standard deviation of the measurement errors, and $r_{N}$ is the random variable with normal distribution, mean zero and unit standard deviation.

For illustration of the proposed methodology, the synthetic experimental measurements were obtained from twenty values of residence time and, consequently, twenty different volumetric flow rates for the triglyceride species.

It was considered a typical value of the experimental standard deviation, to be used in the generation of the synthetic simulated measurements, of $5 \%$ of the maximum value of the concentration measurements for each species. Table 8 shows the standard deviation for each of the species here considered.
Table 8 - Dimensionless standard deviation of the species concentrations measurements used in the parameter estimation.

\begin{tabular}{ll} 
Species & $\begin{array}{l}\text { Standard deviation of } \\
\text { measurements, } \sigma_{\mathrm{s}, \text { measure }}\end{array}$ \\
\hline Triglycerides & 0.0469 \\
Diglycerides & 0.0111 \\
Monoglycerides & 0.0028 \\
Biodiesel & 0.1261
\end{tabular}

In Table 9 are presented the values of the simulated experimental concentration measurements for each species and Fig. 4(a-d) shows the exact dimensionless concentrations obtained via the 3D model (Pontes et al., 2017) for each species, and the synthetic measurements with their respective standard deviations.

To initialize the Markov chain, different starting values for the Markov Chain were tested and all of them have converged statistically to the same mean, even within a few states, as presented in Fig. $5(\mathrm{a}-\mathrm{f})$. Fig. $5(\mathrm{a}-\mathrm{f})$ presents in red the exact value for each of the six parameters estimated, and the evolution of three posterior Markov Chain departing from three different starting values, namely, $10 \%$ above the exact value (black curve), $10 \%$ below the exact value (blue curve) and $5 \%$ above the exact value (green curve).

Table 10 presents the employed starting values for one of the worst case here tested, namely equal to $10 \%$ less than the exact value of the parameters, and the comparison to the exact values.

The priori probability distribution used for the parameters to be estimated (exponents representation of kinetic coefficients) is a uniform distribution with upper and lower limits $10 \%$ above and $10 \%$ below the original kinetic coefficient value, respectively. Fig. 6 shows the curves referring to, the exact dimensionless concentrations, the mean of the concentrations of the species obtained through uniform distribution samples with intervals of $10 \%$ above and $10 \%$ below the original kinetic coefficient value and the $99 \%$ confidence interval.

In the convergence analysis of the posterior of the parameters it has been used 100,000 states of the Markov chain. The adopted search step is $1.5 \times 10^{-3}$, with an acceptance rate of

Table 9 - Synthetic measurements of each dimensionless species concentration.

\begin{tabular}{|c|c|c|c|c|c|}
\hline Res. time (min) & $\mathrm{Q}_{\mathrm{TG}}(\mathrm{ml} / \mathrm{min})$ & $\mathbf{Y}_{\text {TG }}$ & $Y_{\mathrm{DG}}$ & $\mathbf{Y}_{\mathrm{MG}}$ & $\mathbf{Y}_{\mathbf{B}}$ \\
\hline 0.5 & 0.399 & 0.9911 & 0.0657 & 0.0066 & 0.1396 \\
\hline 1.0 & 0.199 & 0.8283 & 0.1104 & 0.0368 & 0.4974 \\
\hline 1.5 & 0.133 & 0.6935 & 0.1546 & 0.0449 & 0.4678 \\
\hline 3.0 & 0.066 & 0.4640 & 0.2256 & 0.0530 & 0.7586 \\
\hline 3.5 & 0.0570 & 0.4058 & 0.2103 & 0.0520 & 1.0773 \\
\hline 4.0 & 0.0498 & 0.3518 & 0.1900 & 0.0472 & 1.2714 \\
\hline 5.5 & 0.0362 & 0.3051 & 0.1575 & 0.0384 & 1.4129 \\
\hline 6.5 & 0.0307 & 0.2749 & 0.1475 & 0.0298 & 1.7752 \\
\hline 8.0 & 0.0249 & 0.3036 & 0.1297 & 0.0308 & 2.0058 \\
\hline 8.5 & 0.0234 & 0.2075 & 0.1072 & 0.0262 & 2.0986 \\
\hline 9.5 & 0.0210 & 0.2029 & 0.0972 & 0.0282 & 2.1928 \\
\hline 10.0 & 0.0199 & 0.2281 & 0.1215 & 0.0257 & 2.2716 \\
\hline 12.0 & 0.0166 & 0.0827 & 0.0770 & 0.0272 & 2.2679 \\
\hline 13.5 & 0.0148 & 0.0980 & 0.1013 & 0.0229 & 2.4319 \\
\hline 14.0 & 0.0142 & 0.0689 & 0.1007 & 0.0217 & 2.5542 \\
\hline 14.5 & 0.0137 & 0.1588 & 0.0900 & 0.0207 & 2.5178 \\
\hline 16.0 & 0.0125 & 0.0905 & 0.0721 & 0.0259 & 2.4123 \\
\hline 17.5 & 0.0114 & 0.1237 & 0.0951 & 0.0207 & 2.3492 \\
\hline 18.5 & 0.0108 & 0.0505 & 0.0690 & 0.0228 & 2.6239 \\
\hline 19.0 & 0.0105 & 0.1069 & 0.0551 & 0.0241 & 2.4345 \\
\hline
\end{tabular}



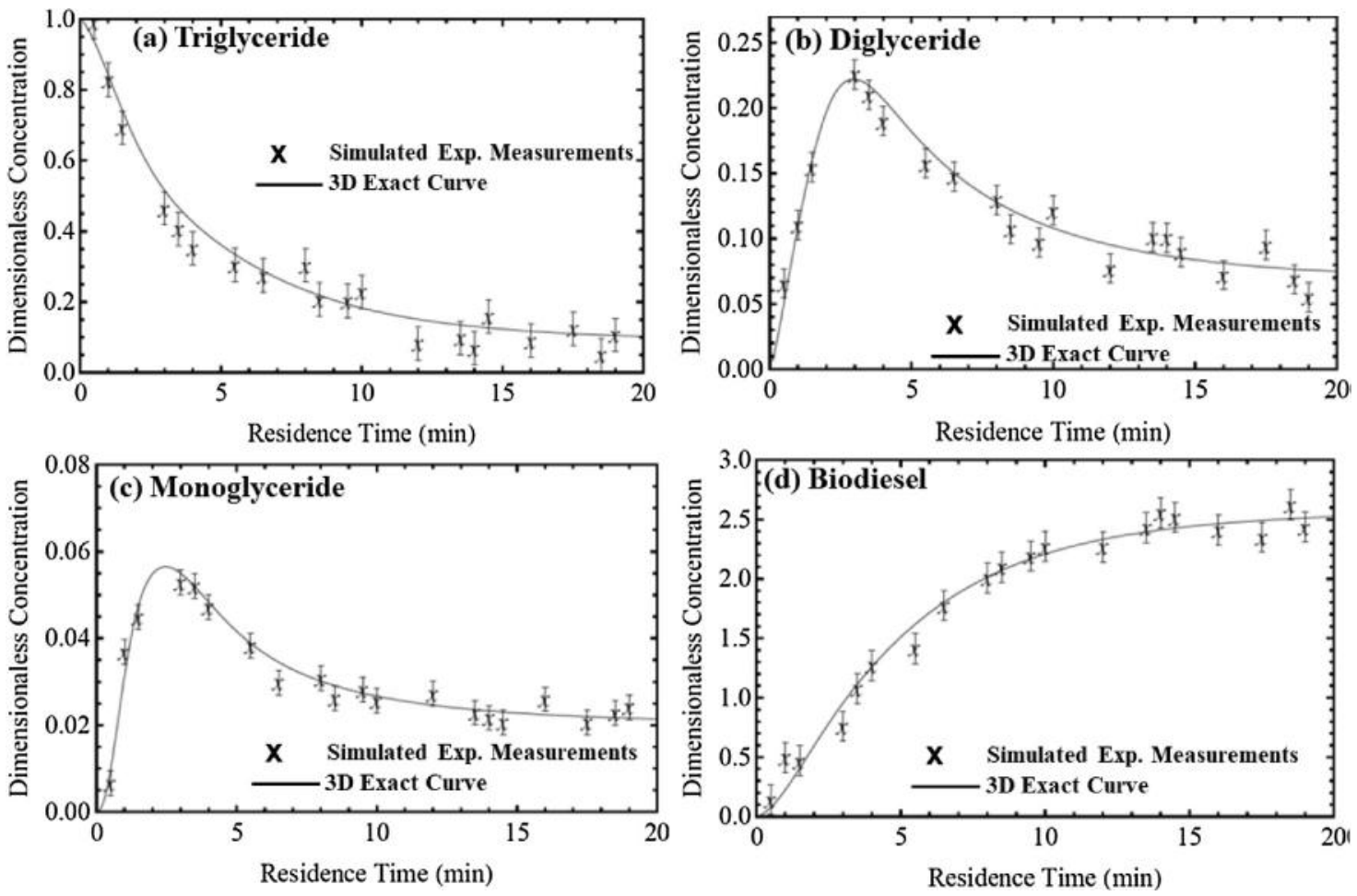

Fig. 4 - Simulated experimental measurements of species concentrations (symbol $\mathbf{x}$ ) and calculated species concentration evolutions, with the exact parameters, generated by the 3D mathematical model (Pontes et al., 2017), solid lines: (a) Triglyceride; (b) Diglyceride; (c) Monoglyceride; and (d) Biodiesel.

Table 10 - Exact and initial values of the parameters and the respective values of the kinetic coefficients.

\begin{tabular}{llllll} 
Parameters (Exponents) & InitialValue & ExactValue & Kinetic coefficients & InitialValue $\left[\mathrm{m}^{3} /(\mathrm{mol} . \mathrm{s})\right]$ & ExactValue $\left[\mathrm{m}^{3} /(\mathrm{mol} . \mathrm{s})\right]$ \\
\hline$\overline{\mathbf{k}}_{1}$ & -5.89 & -5.36 & $\mathrm{k}_{1}$ & $1.271 \times 10^{-6}$ & $4.368 \times 10^{-6}$ \\
$\overline{\mathbf{k}}_{2}$ & -5.52 & -5.02 & $\mathrm{k}_{2}$ & $3.031 \times 10^{-6}$ & $9.623 \times 10^{-6}$ \\
$\overline{\mathbf{k}}_{3}$ & -5.20 & -4.73 & $\mathrm{k}_{3}$ & $6.332 \times 10^{-6}$ & $1.88 \times 10^{-5}$ \\
$\overline{\mathbf{k}}_{4}$ & -4.36 & -3.97 & $\mathrm{k}_{4}$ & $4.306 \times 10^{-5}$ & $1.074 \times 10^{-4}$ \\
$\overline{\mathbf{k}}_{5}$ & -5.14 & -4.67 & $\mathrm{k}_{5}$ & $7.216 \times 10^{-6}$ & $2.117 \times 10^{-5}$ \\
$\overline{\mathbf{k}}_{6}$ & -6.65 & -6.05 & $\mathrm{k}_{6}$ & $2.237 \times 10^{-7}$ & $9.0 \times 10^{-7}$ \\
\hline
\end{tabular}

55.39\%. Fig. 7 (a-f) show the Markov chains for the respective parameter along the states for the case of the starting condition equal to $10 \%$ less than the exact value of the parameters. It is possible to perceive the convergence of all the parameter chains, even for just a few states of the Markov chain, less than 5,000, and converge to the exact values (red line) used in the generation of the simulated experimental data.

Fig. 8 shows the objective function along the states of the Markov chain for the case of considering the starting condition equal to $10 \%$ less than the exact value of the parameters, where one may observe the rapid convergence of the objective function to its minimum value within few states. The objective function is given by:

$$
\left[\mathrm{Y}-\overline{\mathrm{F}}_{\mathrm{S}}(\mathrm{P})\right]^{\mathrm{T}} \mathrm{W}^{-1}\left[\mathrm{Y}-\overline{\mathrm{F}}_{\mathrm{S}}(\mathrm{P})\right]
$$

Based on the analysis of the evolution of the Markov chains, after converging for all parameters and for the objective function, it is assumed that the Markov chains require 5000 heating states. The analyzes of the parameter estimation is performed through means and quantiles of $99 \%$ of the samples. Table 11 presents the averages of the estimated parameters, the exact value of the parameters, and the relative error between them.
Table 11 - Averages of the estimated parameters, the exact value of the parameters, and the relative errors.

\begin{tabular}{lllll} 
Parameter & Exact & Estimated & Relative error (\%) & Quantile (99\%) \\
\hline$\overline{\mathbf{k}}_{1}$ & -5.36 & -5.43 & 1.313 & $(-5.470 ;-5.362)$ \\
$\overline{\mathbf{k}}_{2}$ & -5.02 & -5.08 & 1.312 & $(-5.155 ;-4.968)$ \\
$\overline{\mathbf{k}}_{3}$ & -4.73 & -4.69 & 0.738 & $(-4.795 ;-4.493)$ \\
$\overline{\mathbf{k}}_{4}$ & -3.97 & -3.93 & 0.970 & $(-4.053 ;-3.708)$ \\
$\overline{\mathbf{k}}_{5}$ & -4.67 & -4.71 & 0.890 & $(-4.752 ;-4.655)$ \\
$\overline{\mathbf{k}}_{6}$ & -6.05 & -6.08 & 0.551 & $(-6.137 ;-5.987)$ \\
\hline
\end{tabular}

It is also noticed that the relative errors of the estimated parameters vary between $0.551 \%$ for the parameter $\overline{\mathrm{k}_{6}}$ and $1.313 \%$ for the parameter $\overline{\mathrm{k}_{1}}$ for the case of considering the starting condition equal to $10 \%$ less than the exact value of the parameters. Table 12 shows the averages of the kinetic coefficients, obtained by means of the estimated parameters, the exact value of the kinetic coefficients, and the corresponding relative error, again for the same case of considering the starting condition equal to $10 \%$ less than the exact value of the parameters.

The estimated concentration evolutions of species TG, DG, MG, B, GL and A at the exit of the micro-channel $(X=1)$ are shown in Fig. $9(a-f)$, where it is observed an excellent agreement of the estimated concentrations with 

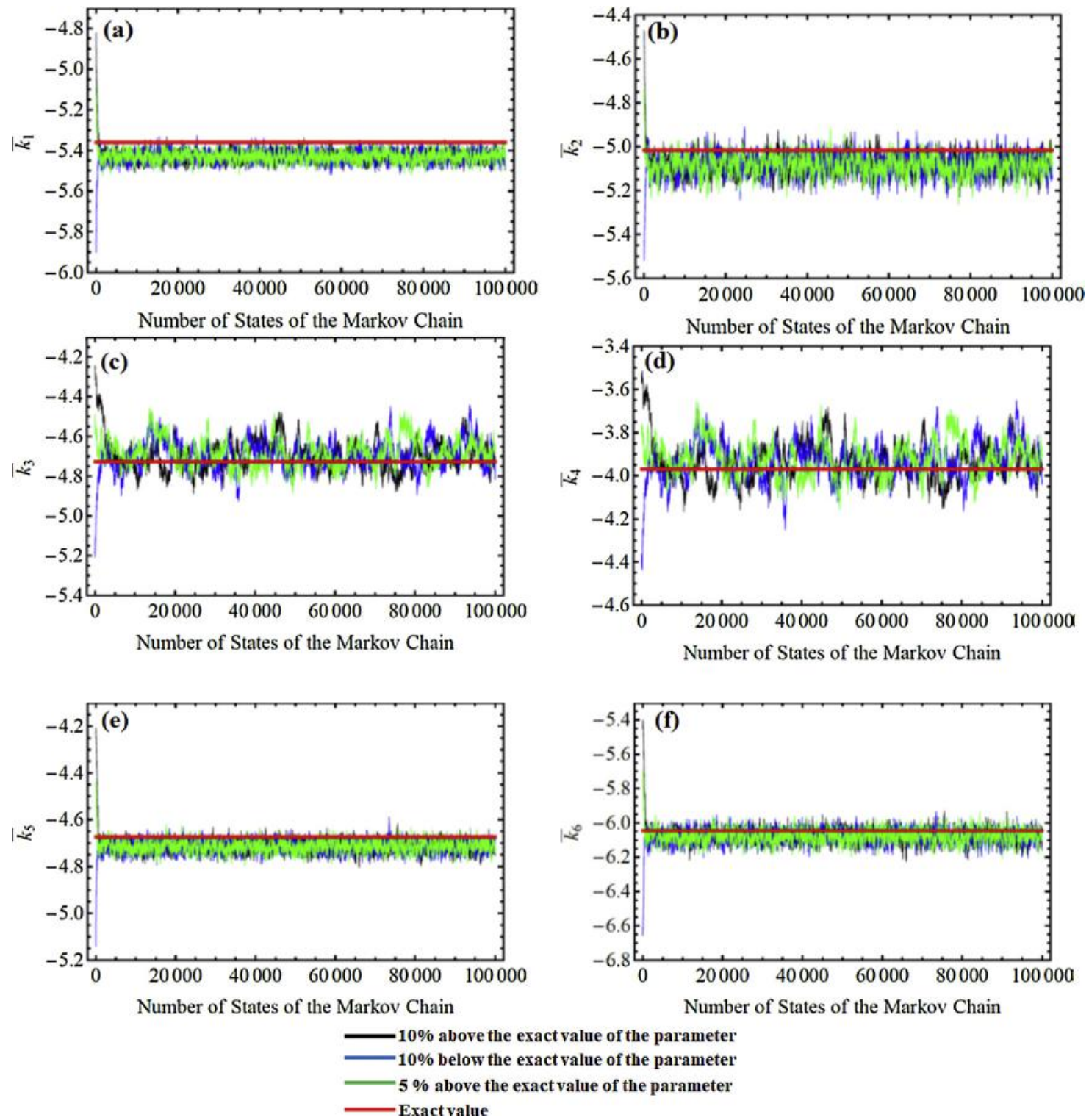

Fig. 5 - Posterior Markov Chains for the six estimated exponents of the six kinetic coefficients, departing from different initial values. The exact value (red curve), $10 \%$ above the exact value (black curve), $10 \%$ below the exact value (blue curve) and $5 \%$ above the exact value (green curve). (a); (b); (c); (d); (e)and (f).

Table 12 - Averages of the kinetic coefficients obtained through the estimated parameters, the exact value of the kinetic coefficients, and the relative errors.

\begin{tabular}{lllll} 
Kinetic coefficients & Exact $\left[\mathrm{m}^{3} /(\mathrm{mol} . \mathrm{s})\right]$ & Estimated $\left[\mathrm{m}^{3} /(\mathrm{mol} . \mathrm{s})\right]$ & Relative Error(\%) \\
\hline $\mathrm{k}_{1}$ & $4.368 \times 10^{-6}$ & $3.720 \times 10^{-6}$ & 14.82 & $\left(3.389 \times 10^{-6}, 4.340 \times 10^{-6}\right)$ \\
$\mathrm{k}_{2}$ & $9.623 \times 10^{-6}$ & $8.311 \times 10^{-6}$ & 13.63 & $\left(6.995 \times 10^{-6}, 10.76 \times 10^{-6}\right)$ \\
$\mathrm{k}_{3}$ & $1.88 \times 10^{-5}$ & $2.063 \times 10^{-5}$ & 9.76 & $\left(1.604 \times 10^{-5}, 3.213 \times 10^{-5}\right)$ \\
$\mathrm{k}_{4}$ & $1.074 \times 10^{-4}$ & $1.194 \times 10^{-4}$ & 11.2 & $\left(0.885 \times 10^{-4}, 1.959 \times 10^{-4}\right)$ \\
$\mathrm{k}_{5}$ & $2.117 \times 10^{-5}$ & $1.926 \times 10^{-5}$ & 9.01 & $\left(1.770 \times 10^{-5}, 2.212 \times 10^{-5}\right)$ \\
$\mathrm{k}_{6}$ & $9.0 \times 10^{-7}$ & $8.363 \times 10^{-7}$ & 7.07 & $\left(7.292 \times 10^{-7}, 1.031 \times 10^{-6}\right)$ \\
\hline
\end{tabular}

the simulated experimental measurements generated by the three-dimensional model and with the exact curves of the concentrations reconstructed with the reduced model and the estimated average kinetic coefficients. The credibility interval was calculated by the quantile of the posterior sample.

Fig. 10(a-d) show the residuals for the estimated average concentrations of the four species. Residuals are calculated by the difference between the estimated species concentration obtained from the parameter's values obtained in the estimation process, and the exact concentrations obtained by the three-dimensional model. It is observed that the resid- uals have a fairly low magnitude throughout the residence time domain here considered. In addition, through analysis of the residuals, one can conclude that the results are correlated, confirming that the reduced model derived via CIEA is adequate for the proposed estimation of the parameters.

\section{Conclusions}

The inverse problem considered in this work was the estimation of the kinetic coefficients present in the biodiesel synthesis from soybean oil and methanol in a micro-reactor, 

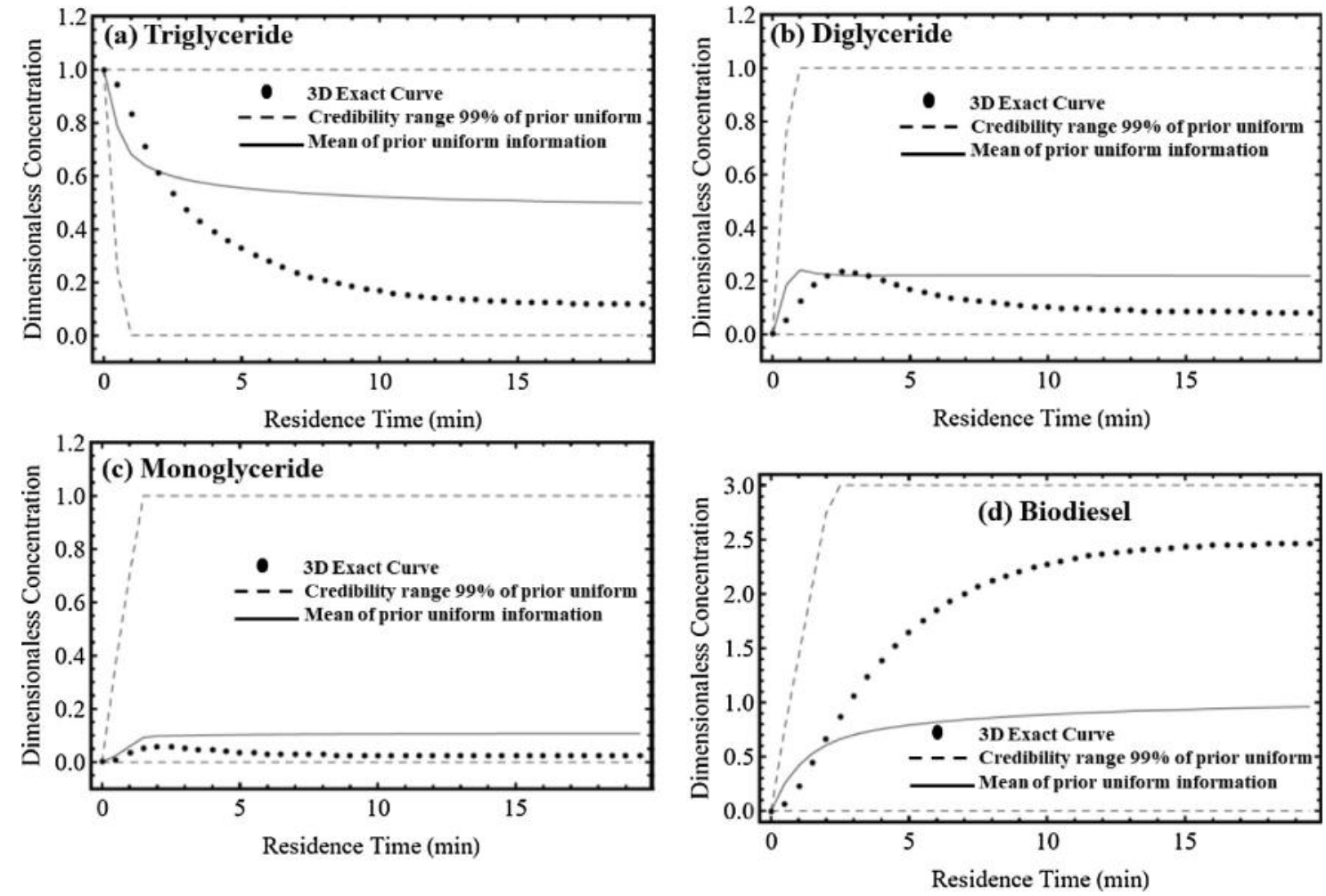

Fig. 6 - Curves referring to, the exact dimensionless concentrations, the mean of the concentrations of the species obtained through uniform distribution.
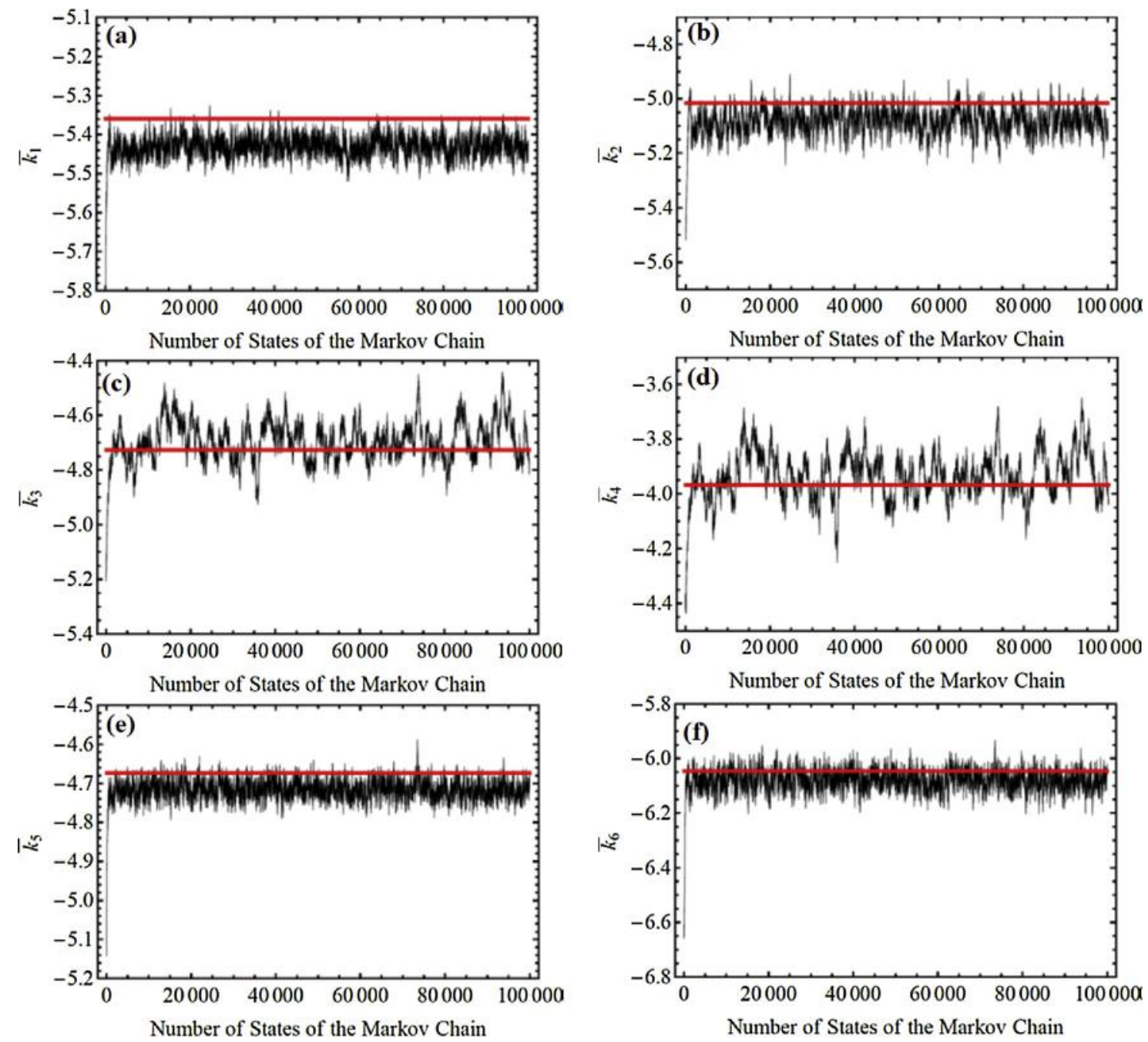

Fig. 7 - Markov Chain states evolutions for the six parameters: (a) $\bar{k}_{1}$; (b) $\bar{k}_{2}$; (c) $\bar{k}_{3}$; (d) $\bar{k}_{4}$; (e) $\bar{k}_{5}$ and (f) $\bar{k}_{6}$. 


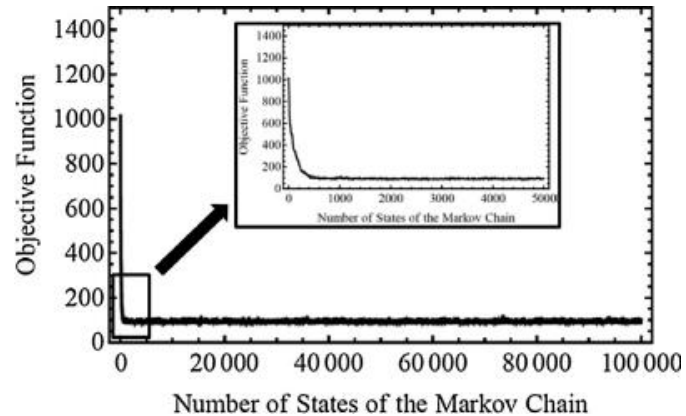

Fig. 8 - Convergence of the objective function.

employing measurements of four species, namely, triglyceride, diglyceride, monoglyceride, and biodiesel. The direct problem was handled by a reduced nonlinear model based on a coupled first order ODEs system, obtained from the lumped-differential reformulation of the three-dimensional nonlinear coupled mathematical model (Pontes et al., 2015) using the Coupled Integral Equations Approach (CIEA). In the reformulation procedure a $\mathrm{H}_{1,1}$ approximation, equivalent to a corrected trapezoidal rule approximation, was used for the definition of the average concentrations, while the $\mathrm{H}_{0,0}$ approximation, equivalent to the plain trapezoidal
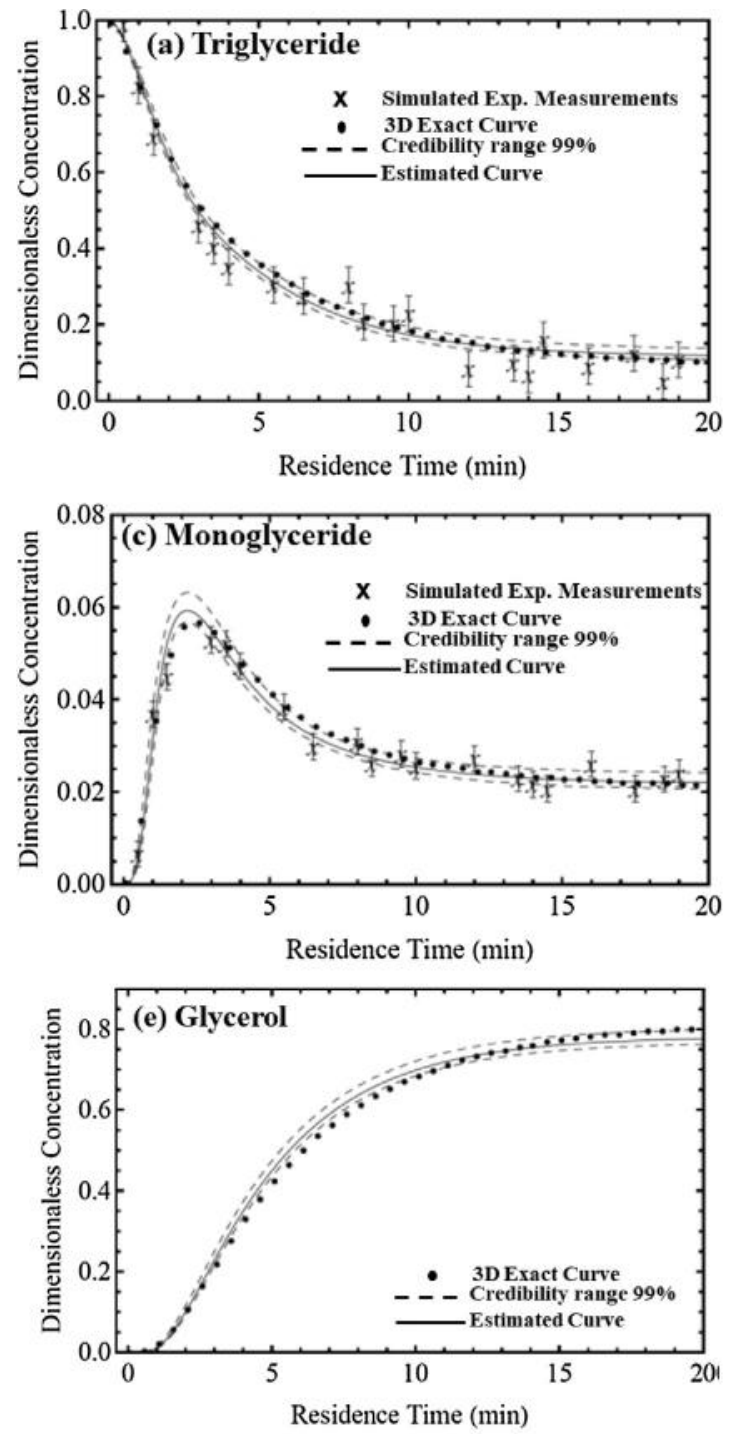

rule, was employed for the mass fluxes. The order of the approximations could be further increased, for instance a $\mathrm{H}_{2,2}$ approximation for the concentration or $\mathrm{H}_{1,1}$ approximation for the flux, what would lead to additional equations for the boundary concentrations. This is would be feasible, and certainly more accurate than the present approximation and less costly than solving the original PDEs, as shown by Cotta and Mikhailov (1997). However, the aim here was to demonstrate that the improved lumped-differential reformulation could lead to good results, within the same level of mathematical simplification as offered by the classical lumped system analysis. Therefore, the original partial differential equations were reformulated as single ordinary differential equations for the average concentrations, with sufficient precision to allow for a reliable inverse problem analysis. The ODEs system was solved numerically using the NDSolve routine of the Mathematica 10.0 system. The simulated experimental measurements were taken at the microchannel outlet, at $\mathrm{X}=1$, and obtained from the hybrid numerical-analytical integral transforms solution of the three-dimensional nonlinear coupled mathematical model described in (Pontes et al., 2017), thus avoiding the so-called inverse crime. The sensitivity analysis first permitted to demonstrate that the estimation of the kinetic coefficients in algebraic exponential form (base 10),
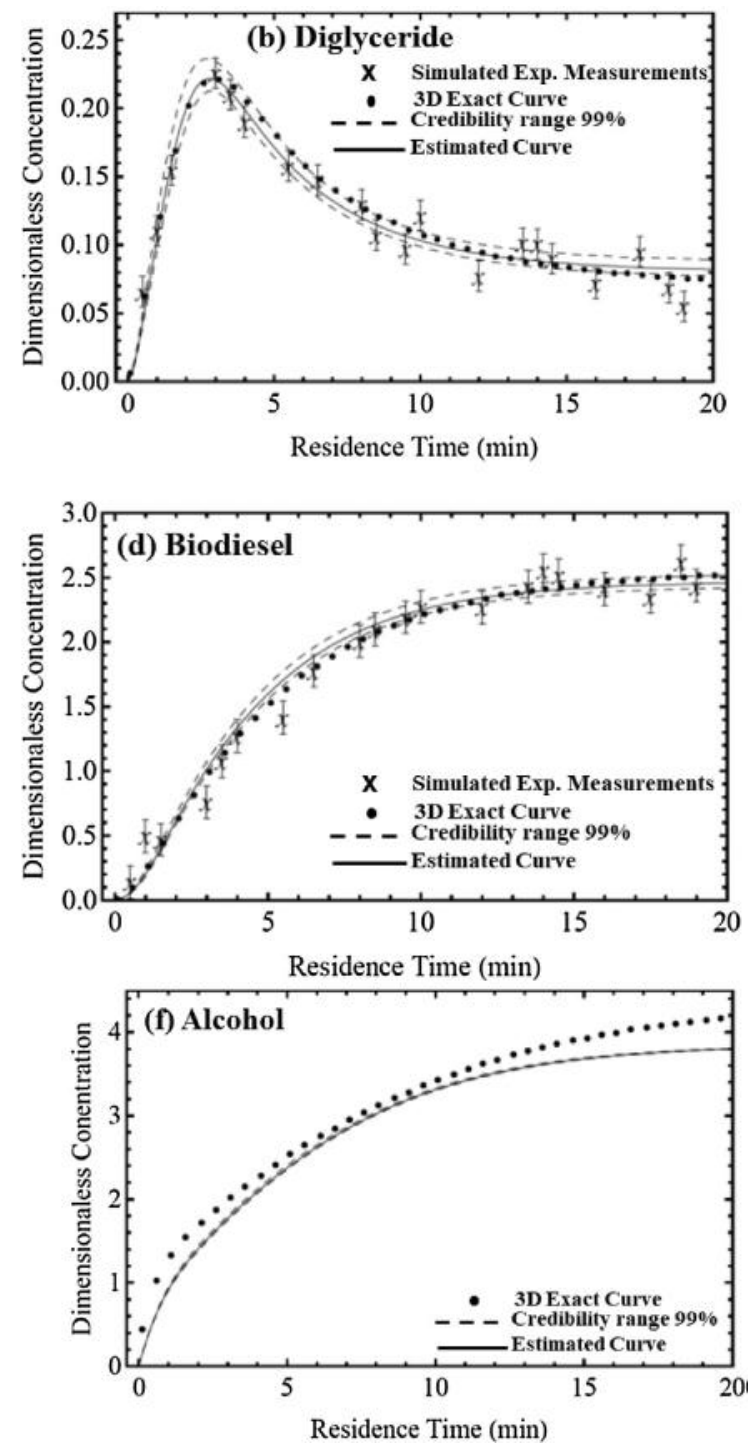

Fig. 9 - Estimated (solid lined) and exact (dots) species concentration evolutions at micro-reactor outlet, with corresponding confidence interval (99\%) curves: (a) Triglyceride, (b) Diglyceride, (c) Monoglyceride and (d) Biodiesel . 

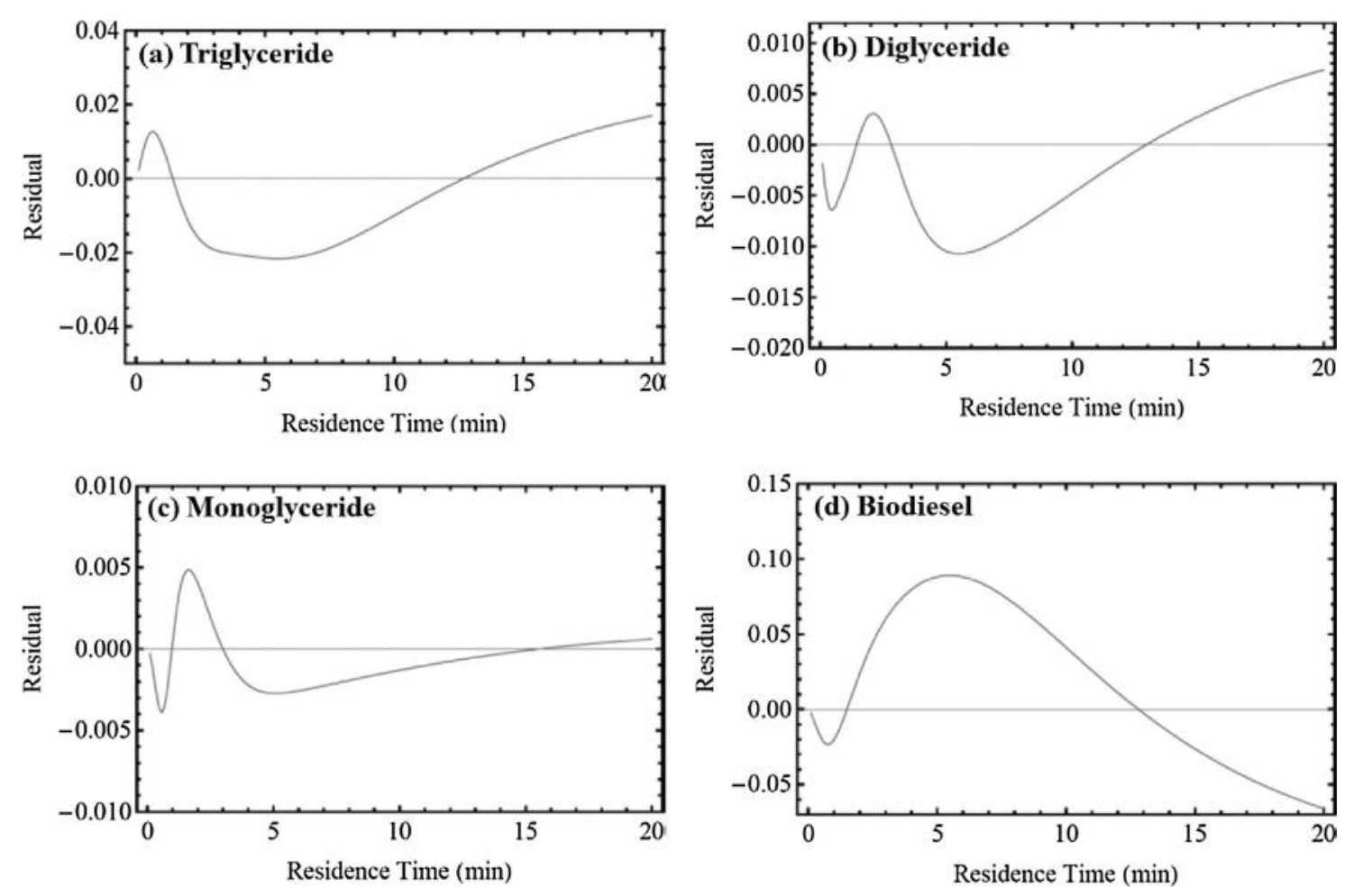

Fig. 10 - Residuals for the estimated average species concentration: (a) Triglyceride; (b) Diglyceride; (c) Monoglyceride; and (d) Biodiesel.

would lead to higher values of the reduced sensitivity coefficients, thus recommending that the procedure be undertaken for the estimation of the exponents in this alternative representation. It also showed that in principle only one parameter has no linear dependence and, in the analysis of the magnitude of the determinant of the $\mathrm{J}^{\mathrm{T}} \mathrm{J}$ matrix, it was verified that using the measurements for all the species (A, TG, DG, MG, B and GL), the estimates would be most reliable, thus it would be desirable to employ experiments at lower residence times when full conversion of triglycerides to biodiesel is not yet achieved. However, since during the experimental process of obtaining biodiesel samples it is not convenient to obtain glycerol (GL) and alcohol (A) information, once these species are extracted from the final product of the biodiesel synthesis, the inverse problem analysis was undertaken considering only simulated measurements of the four species (TG, DG, MG and $\mathrm{B})$.

The inverse problem was solved using the Markov Chain Monte Carlo method, using non-informative uniform priori. The results obtained with simulated measurements showed that the MCMC method together with the reduced lumpeddifferential model was able to provide accurate and stable estimates for the six unknown kinetic coefficients with a noninformative a priori information.

\section{Acknowledgements}

The authors would like to acknowledge the partial financial support provided by the Brazilian agencies (CAPES, CNPq, FAPERJ, and ANP PRH-37).

\section{References}

Al-Dhubabian, A.A., 2005. Production of Biodiesel from Soybean Oil in a Micro Scale Reactor. (M.Sc. Thesis). Oregon State University Corvallis, OR, USA.
Aparecido, J.B., Cotta, R.M., 1989. Improved one-dimensional fin solutions. Heat Transfer Eng. 11 (1), 49-59.

Arias, E.L.M., Martins, P.F., Munhoz, A.L.J., Gutierrez-Rivera, L., Maciel Filho, R., 2012. Continuous synthesis and in situ monitoring of biodiesel production in different microfluidic devices. Ind. Eng. Chem. Res. 51, 10755-10767.

Billo, R.E., Oliver, C.R., Charoenwat, R., Dennis, B.H., Wilson, P.A., Priest, J.W., Beardsley, H., 2015. A cellular manufacturing process for a full scale biodiesel microreactor. J. Manuf. Syst. 37, 409-416.

Bothe, D., Stemich, C., Warnecke, H.J., 2008. Computation of scales and quality of mixing in a T-shaped microreactor. Comput. Chem. Eng. 32, 108-114.

Charoenwat, R., Dennis, B.H., 2009. Transesterification of Vegetable Oils with a Continuous Flow Capillary Reactor. In: Proceedings of the ASME Early Career Technical Conference, Arlington, TX.

Cotta, R.M., 1990. Hybrid numerical-analytical approach to nonlinear diffusion problems. Numer. Heat Transfer Fundam. 127, 217-226.

Cotta, R.M., 1993. Integral Transforms in Computational Heat and Fluid Flow. CRC Press, Boca Raton, FL, USA.

Cotta, R.M., Mikhailov, M.D., 1997. Heat Conduction: Lumped Analysis, Integral Transforms Symbolic Computation. John Wiley \& Sons, New York, NY, USA.

Demirbas, A., 2008. Comparison of transesterification methods for production of biodiesel from vegetable oils and fats. Energy Convers. Manage. 49, 125-130.

Dennis, B.H., Jin, W., Cho, J., Timmons, R.B., 2008. Inverse determination of kinetic rate constants for transesterification of vegetable oils. Inverse Prob. Sci. Eng. 16 (6), 693-704.

Falahati, H., Tremblay, A.Y., 2012. The effect of flux and residence time in the production of biodiesel from various feedstocks using a membrane reactor. Fuel 91 (1), 126-133.

Galante, R.M., 2012. Modeling and Simulation of a Continuous Tubular Reactor for Biodiesel Production, PhD Thesis. Chemical Engineering Program Federal, University of Santa Catarina, SC/Brazil.

Gamerman, D., Lopes, H.F., 2006. Markov Chain Monte Carlo: Stochastic Simulation for Bayesian Inference, Second ed. Chapman \& Hall/CRC, Boca Raton, FL. 
Gomez-Castro, F.I., Rico-Ramirez, V., Segovia-Hernandez, J.G., Hernandez-Castro, S., El-Halwagi, M.M., 2013. Simulation study on biodiesel production by reactive distillation with methanol at high pressure and temperature: impact on costs and pollutant emissions. Comput. Chem. Eng. 52, 204-215.

Guan, G., Kusakabe, K., Moriyama, K., Sakurai, N., 2009. Transesterification of sunflower oil with methanol in a micro-tube reactor. Ind. Eng. Chem. Res. 48, 1357-1363.

Hessel, V., Lowe, H., Schonfeld, F., 2005. Micromixers - a review on passive and active mixing principles. Chem. Eng. Sci. 60, 2479-2501.

Kaipo, J.P., Somersalo, E., 2004. Computational and Statistical Methods for Inverse Problems. Springer, Berlin.

Kakaç, S., Yener, Y., Naveira-Cotta, C.P., 2018. Heat Conduction, 5th edition. Taylor and Francis, ISBN 9781138943841.

Kobayashi, J., Mori, Y., Kobayashi, S., 2006. Multiphase organic synthesis in microchannel reactors. Chem. Asian J. 1, 22-35.

Kumar, V., Paraschivoiu, M., Nigam, K.D.P., 2011. Single-phase fluid flow and mixing in microchannels. Chem. Eng. Sci. 66, 1329-1373.

Lee, C.Y., Chang, C.L., Wang, Y.N., Fu, L.M., 2011. Microfluidic mixing: a review. Int. J. Mol. Sci. 12, 3263-3287.

Leung, D.Y.C., Wu, X., Leung, M.K.H., 2010. A review on biodiesel production using catalyzed transesterification. Appl. Energy 87, 1083-1095.

Liang, F., Liu, C., Carroll, R.J., 2010. Advanced Markov Chain Monte Carlo methods: Learning from Past Samples. John Wiley and Sons Ltd.

Ma, F., Hanna, M.A., 1999. Biodiesel production: a review. Bioresour. Technol. 70, 1-15.

Meher, L.C., Sagar, D.V., Naik, S.N., 2006. Technical aspects of biodiesel production by transesterificaton - a review. Renewable Sustainable 10, 248-268.

Naveira, C.P., Lachi, M., Cotta, R.M., Padet, J., 2009. Hybrid formulation and solution for transient conjugated conduction-external convection. Int. J. Heat Mass Transfer 52 (1-2), 112-123.

Naveira-Cotta, C.P., Tostado, C.P., Costa Jr., J.M., Nunes, J.S., 2015. Micro-reactors for biodiesel synthesis: design fabrication, and characterization. Heat Pipe Sci. Technol. Int. J. 6 (3-4), 135-153.

Noureddini, H., Zhu, D., 1997. Kinetics of transesterification of soybean oil. J. Am. Oil Chem. Soc. 74 (11), 1457-1463.

Orlande, H.R.B., Colaço, M.J., Naveira-Cotta, C.P., Guimarães, G., Borges, V.L., 2011. Inverse Problems in Heat Transfer. SBMAC (In Portuguese), São Carlos, SP Brasil.

Özisik, M.N., Orlande, H.R.B., 2000. Inverse Heat Transfer: Fundamentals and Application. Taylor \& Francis, New York.

Pengmei, L., Yuan, Z., Lianhua, L., Zhongming, W., Wen, L., 2010. Biodiesel from different oil using fixed-bed and plug-flow reactors. Renewable Energy 35 (1), 283-287.

Pontes, P.C., Naveira- Cotta, C.P., Macêdo, E.N., Quaresma, J.N.N., 2015. Integral transforms analysis of three-dimensional mass transfer in the transesterification process in micro-reactors.
In: Proceedings of the International Symposium on Advances in Computational Heat Transfer - ICHMT, Piscataway, USA MAY.

Pontes, P.C., Chen, K., Naveira-Cotta, C.P., Costa Junior, J.M., Tostado, C.P., Quaresma, J.N.N., 2016. Mass transfer simulation of biodiesel synthesis in micro-reactors. Comput. Chem. Eng. 93, 36-51.

Pontes, P.C., Naveira-Cotta, C.P., 2016. Inverse problem analysis for identification of reaction kinetics constants in micro-reactors for biodiesel synthesis. J. Phys. Conf. Ser. 745, p. 032101.

Pontes, P.C., Naveira-Cotta, C.P., Quaresma, J.N.N., 2017. Three-dimensional reaction-convection-diffusion analysis with temperature influence for biodiesel synthesis in micro-reactors. Int. J. Therm. Sci. 118, 1-19.

Rahimi, M., Aghel, B., Alitabar, M., Sepahvand, A., Ghasempour, H.R., 2014. Optimization of biodiesel production from soybean oil in a micro-reactor. Energy Convers. Manage. 79, 599-605.

Richard, R., Thiebaud-Roux, S., Prat, L., 2013. Modelling the kinetics of transesterification reaction of sunflower oil with ethanol in micro-reactors. Chem. Eng. Sci. 87, 258-269.

Santana, H.S., Tortola, D.S., Reis, E.M., Silva Jr, J.L., Taranto, O.P., 2016. Transesterification reaction of sunflower oil and ethanol for biodiesel synthesis in microchannel reactor: experimental and simulation studies. Chem. Eng. J. 302, 752-762.

Santana, H.S., Tortola, D.S., Silva Jr., J.L., Taranto, O.P., 2017. Biodiesel synthesis in micromixer with static elements. Energy Convers. Manage. 141, 28-39.

Schwarz, S., Borovinskaya, E.S., Reschetilowski, W., 2013. Base catalyzed ethanolysis of soybean oil in micro-reactors: experiments and kinetic modeling. Chem. Eng. Sci. 104, 610-618.

Silva, N.L., Rivera, E.C., Batistella, C.B., Lima, D.R., Maciel Filho, R., Maciel, M.R.W., 2008. Biodiesel production from vegetable oils: operational strategies for large scale systems. Proceedings of the 18th European Symposium on Computer Aided Process Engineering -ESCAPE18.

Sphaier, L.A., Su, J., Cotta, R.M., et al., 2017. Macroscopic Heat Conduction Formulation. In: Francis, A., Kulacki (Eds.), Handbook of Thermal Science and Engineering. Springer International Publishing, Chapter 4.

Sun, J., Ju, J., Ji, L., Zhang, L., Xu, N., 2008. Synthesis of biodiesel in capillary micro-reactors. Ind. Eng. Chem. Res. 47, 1398-1403.

Sun, P., Wang, B., Yao, J., Zhang, L., Xu, N., 2010. Fast synthesis of biodiesel at high throughput in micro-structured reactors. Ind. Eng. Chem. Res. 49, 1259-1264.

Tiwari, A., Rajesh, V.M., Yadav, S., 2018. Biodiesel production in micro-reactors: a review. Energy Sustainable Dev. 43.

Wen, Z., Yu, X., Tu, S.T., Yan, J., Dahlquist, E., 2009. Intensification of biodiesel synthesis using zigzag micro-channel reactors. Bioresource Technol. 100, 3054-3060.

Wolfram, S., 2017. Wolfram Mathematica, Version 11. Wolfram Research Inc., Champaign, IL, USA.

Xie, T., Lixiong, Z., Nanping, X., 2012. Biodiesel synthesis in micro-reactors. Green Process Synth. 1, 61-70. 